\title{
Knockdown of Tousled-like kinase 1 inhibits survival of glioblastoma multiforme cells
}

\author{
KAMARIAH IBRAHIM ${ }^{1,2}$, NOR AZIAN ABDUL MURAD ${ }^{1}$, ROSLAN HARUN $^{3}$ and RAHMAN JAMAL ${ }^{1,4}$ \\ ${ }^{1}$ UKM Medical Molecular Biology Institute, Universiti Kebangsaan Malaysia, Kuala Lumpur 56000; \\ ${ }^{2}$ Department of Biomedical Science, Faculty of Medicine, University of Malaya, Kuala Lumpur 50603; \\ ${ }^{3}$ KPJ Ampang Puteri Specialist Hospital, Ampang, Selangor 68000; ${ }^{4}$ Faculty of Medicine, \\ Universiti Kebangsaan Malaysia, Kuala Lumpur 56000, Malaysia
}

Received May 13, 2019; Accepted January 17, 2020

DOI: $10.3892 /$ ijmm.2020.4619

\begin{abstract}
Glioblastoma multiforme (GBM) is an aggressive type of brain tumour that commonly exhibits resistance to treatment. The tumour is highly heterogenous and complex kinomic alterations have been reported leading to dysregulation of signalling pathways. The present study aimed to investigate the novel kinome pathways and to identify potential therapeutic targets in GBM. Meta-analysis using Oncomine identified 113 upregulated kinases in GBM. RNAi screening was performed on identified kinases using ON-TARGETplus siRNA library on LN18 and U87MG. Tousled-like kinase 1 (TLK1), which is a serine/threonine kinase was identified as a potential hit. In vitro functional validation was performed as the role of $T L K 1$ in GBM is unknown. TLK1 knockdown in GBM cells significantly decreased cell viability, clonogenicity, proliferation and induced apoptosis. TLK1 knockdown also chemosensitised the GBM cells to the sublethal dose of temozolomide. The downstream pathways of TLK1 were examined using microarray analysis, which identified the involvement of DNA replication, cell cycle and focal adhesion signalling pathways. In vivo validation of the subcutaneous xenografts of stably transfected sh-TLK1 U87MG cells demonstrated significantly decreased tumour growth in female BALB/c nude mice. Together, these results suggested that TLK1 may serve a role in GBM survival and may serve as a potential target for glioma.
\end{abstract}

Correspondence to: Professor Rahman Jamal, Faculty of Medicine, Universiti Kebangsaan Malaysia, Jalan Yaacob Latif, Bandar Tun Razak, Cheras, Kuala Lumpur 56000, Malaysia

E-mail: rahmanj@ppukm.ukm.edu.my

Dr Roslan Harun, KPJ Ampang Puteri Specialist Hospital, Jalan Memanda 9, Taman Dato, Ahmad Razali, Ampang, Selangor 68000, Malaysia

E-mail: drroslan@gmail.com

Key words: glioblastoma, tousled like kinase 1, survival pathway

\section{Introduction}

Glioblastoma multiforme (GBM), is the most lethal human cancer with very poor prognosis even following surgery and chemotherapy. The majority of the primary GBM arises de novo and develops progressively without recognisable symptoms or precursor lesions. Despite advancement in GBM detection, radiation, chemotherapy and surgery, the outcome of GBM remains poor, with an overall survival of only 14 months (1-3).

A higher degree of infiltration is one of the hallmarks of GBM. It rarely metastasises outside the brain but actively migrates through two types of extracellular spaces in the brain: The perivascular space around all blood vessels, and spaces between the neurons and glial cells (2). In order to invade through these spaces, GBM cells have to undergo several biological changes, including gaining mobility, the ability to degrade the extracellular matrix (ECM) and the ability to acquire stem cell phenotype (4). Invasion involves a complicated mechanism comprising cross-talk between canonical pathways in cancer (2). For example, activating epidermal growth factor receptor $(E G F R)$ mutations may result in increased expression and phosphorylation of cell adhesion molecules, thereby increasing GBM invasiveness (5). In addition, tumor protein p53 (TP53) mutations accelerate GBM invasion by facilitating the recycling of integrin, a class of cell surface receptor that forms a network with ECM during cell migration (6). In addition, aberrant AKT signalling increases metalloproteases activity, which subsequently increases the tumour cell proteolytic capability to invade the border of the normal brain tissue (7).

Research and development for improving GBM survival by targeting kinases involved in specific cancer pathways are active areas of investigation. For example, erlotinib targeting the EGFR pathway and bevacizumab targeting the VEGFR and PI3K pathways have both been used to treat GBM. However, clinical trials (clinical trial nos. NCT01110876 and NABTT 0502) showed conflicting results. Erlotinib has been successful in treating lung and breast cancer but not GBM (8). Its poor efficacy in treating GBM is due to the EGFR mutation sites, which occur in the extracellular domain in GBM, whereas in lung cancer, the mutations are at the 
kinase domain (9). Bevacizumab has received an accelerated approval by the United States of America Food and Drug Administration in 2009 due to its success in eradicating recurrent GBM. However, bevacizumab treatment is not beneficial for newly diagnosed patients with GBM (10). Another example of treatment failure is PI3K inhibitors, which primarily target the PI3K class 1 subunit. Despite binding to the PI3K subunits, GBM cells continue to proliferate due to activation of the alternative RAS/MAPK/mitogen-activated protein kinase kinase (MEK) pathway (11). The combination of PI3K and MEK pathway inhibitors has been demonstrated to improve treatment efficacy in GBM (12). However, inhibition of the PI3K will cause downstream independent activation of the AKT pathways or restoration of AKT function involving molecules such as upregulation of receptor tyrosine kinase (RTK) and mTORC2 (13), highlighting the insufficiency of inhibiting PI3K signalling pathways as a singular treatment strategy, and the need to identify an alternative target. Advanced biotechnology platforms as well as integrative analysis tools allow the identification of novel kinome pathways for GBM therapy. The results may provide an implicative understanding to target GBM in a highly strategic manner, thereby improving patient survival. The present study aimed to identify novel kinase targets via RNA interference (RNAi) screening of upregulated kinases identified from meta-analysis, and to validate the functional role of 'hit' target genes, namely Tousled Like Kinase 1 (TLK1), in GBM cells harbouring different types of PTEN and TP53 status by investigating specifically its involvement in GBM cell viability and survival regulations.

\section{Materials and methods}

In silico analysis via Oncomine. Meta-analysis was performed to identify kinases that are involved in GBM using 5 microarray datasets from Oncomine Research Edition (14). Data were obtained from Bredel Brain (15), Liang Brain (16), Shai Brain (17), Lee Brain (18) and Sun Brain (19) datasets. All significantly upregulated kinase genes were selected based on their median rank and $\mathrm{P}<0.05$ (99\% confidence interval). All identified kinases were then compared with those in the Human Kinome Database (www.kinase.com) (20). High-throughput RNAi knockdown of the selected kinases was performed to validate these targets.

Cell culture. The human GBM LN18 (ATCC ${ }^{\circledR}$ CRL-2610 ${ }^{\mathrm{TM}}$ ) and U87MG (ATCC ${ }^{\circledR}$ HTB-14 ${ }^{\mathrm{TM}}$ ) cell lines of an unknown origin were obtained from American Type Culture Collection. The cells were maintained in monolayers in Dulbecco's modified Eagle's medium (DMEM; Sigma-Aldrich; Merk KGaA) containing $10 \%$ foetal bovine serum (Lonza Group Ltd.). The cell lines were routinely maintained at $37^{\circ} \mathrm{C}$ in humidified $5 \% \mathrm{CO}_{2}$. The cells were harvested by removing the medium, washing with $5 \mathrm{ml} 1 \mathrm{X}$ Dulbecco's PBS (Gibco; Thermo Fisher Scientific, Inc.), and trypsinized using 1X TrypLE (Gibco; Thermo Fisher Scientific, Inc.). Normal human astrocytes (NHA; Lonza Group Ltd.) were maintained in monolayers using astrocyte basal medium mixed with AGM $^{\text {тм }}$ BulletKit (Lonza Group Ltd.). The NHA were also routinely maintained at $37^{\circ} \mathrm{C}$ in humidified $5 \% \mathrm{CO}_{2}$. The NHA were harvested and washed using ReagentPack ${ }^{\mathrm{TM}}$ (cat. no. CC-5034; Lonza Group
Ltd.) containing trypsin/ethylenediaminetetraacetic acid (EDTA), trypsin neutralizing solution, and HEPES-buffered saline solution.

RNAi screening. RNAi screening was performed on a ON-TARGETplus SMARTpool Custom reverse transfection format library containing 113 overexpressed kinases genes of interest (GE Healthcare Dharmacon, Inc.) with 6.25 pmol lyophilized small interfering RNA (siRNA) per well in 96-well plates. RNAi screening was performed on 2 different GBM cell lines harbouring 2 different mutations: LN18 cells harbouring TP53 mutation and wild-type PTEN, and U87MG cells harbouring wild-type TP53 and mutant PTEN. Both cell lines were wet reverse-transfected with $0.15 \mu$ l lipophilic base transfection reagent, DharmaFect1 (GE Healthcare Dharmacon, Inc.) according to the manufacturer's protocol, yielding a final concentration of $50 \mathrm{nM}$ siRNA pool per target gene per well. The cells were then incubated at $37^{\circ} \mathrm{C}$ in humidified $5 \% \mathrm{CO}_{2}$ for $48 \mathrm{~h}$ to allow efficient RNA knockdown. Then, the cell culture medium was change and cell viability was measured at $96 \mathrm{~h}$ by adding 1:10 resazurin-based solution, PrestoBlue $^{\circledR}$ (Invitrogen; Thermo Fisher Scientific, Inc.), with $10 \mu l$ dropped into each well. The mixture was incubated for $1 \mathrm{~h}$ at $37^{\circ} \mathrm{C}$. Relative fluorescence unit (RFU) were measured using a Varioskan Flash multimode plate reader (Thermo Fisher Scientific, Inc.) at 560 and $590 \mathrm{~nm}$. All experiments were performed in triplicate. Non-targeting siRNA (si-NTG; GE Healthcare Dharmacon, Inc.) was used as the negative control; PLK1 siRNA (si-PLK1; GE Healthcare Dharmacon, Inc.) was included as the positive control.

Data analysis for RNAi screening. Raw RFU data were log-transformed and the k-Median Absolute Deviation (kMAD) was used for hits identification analysis as it is resistant to outliers in the samples. The kMAD identifies weak hits in RNAi data efficiently compared with the B-score, Z-score, SSMD or mean $+k$ (standard deviations) whilst also capturing strong hits and controlling false positive hits (21-23). As this was a selective RNAi screening strategy, a cut-off of median \pm 'kMAD' was selected for kinase genes to be considered a hit for each screen. Unpaired t-test against the NTG control was also performed to ensure that the target serves a significant role in cancer cell vulnerabilities.

$R N A$ extraction and reverse transcription-quantitative polymerase chain reaction ( $R T-q P C R)$. Transfected cells were harvested at $48 \mathrm{~h}$, and RNA extraction was performed using the RNeasy Plus Mini kit (Qiagen GmbH). cDNA was synthesized using $100 \mathrm{ng}$ of RNA, and generation of cDNA was performed using an iScript ${ }^{\mathrm{TM}}$ cDNA Synthesis kit containing iScript reverse transcriptase (Bio-Rad Laboratories, Inc.). The qPCR was performed using iTaq Universal SYBR Green master mix (Bio-Rad Laboratories, Inc.) on a Rotor-Gene 6000 qPCR platform (Corbett Life Science; Qiagen, Inc.). The forward and reverse $T L K 1$ primers used were 5'-CAG TGGAAGTTTGGAGGGGCCG-3' and 5'-CCGGATGGC GGCGTGTGAT-3', respectively. $\beta$-actin $(A C T B)$ was used as the housekeeping gene, and the forward and reverse primer sequences were 5'-CATGTACGTTGCTATCCAGGC-3' and 5'-CTCCTTAATGTCACGCACGAT-3', respectively. The 
relative gene expression was determined using the comparative threshold cycle $\left(2^{-\Delta \Delta \mathrm{Cq}}\right)$ method (24). The thermocycling conditions for iTaq polymerase activation and denaturation were $95^{\circ} \mathrm{C}$ for $30 \mathrm{sec}$, followed by 40 cycles of denaturation at $95^{\circ} \mathrm{C}(5 \mathrm{sec})$ and annealing/extension at $60^{\circ} \mathrm{C}(30 \mathrm{sec})$, and a final extension at $72^{\circ} \mathrm{C}$ for $60 \mathrm{sec}$. Melt curve analysis was performed at $65-95^{\circ} \mathrm{C}$ with $0.5^{\circ} \mathrm{C}$ increments $(2-5 \mathrm{sec} / \mathrm{step})$. For microarray validation, $\mathrm{qPCR}$ was performed on the selected genes namely; $T L K 1$, Rac family small GTPase 2 (RAC2), Rho associated coiled-coil containing protein kinase 2 , paxillin, collagen type IV $\alpha$ chain, actin related protein $2 / 3$ complex subunit 2, thrombospondin 2 and FYN proto-oncogene, Src family tyrosine kinase.

Protein extraction and western blot analysis. For protein extraction, cells were lysed with radioimmunoprecipitation assay buffer (Thermo Fisher Scientific, Inc.) supplemented with protease cocktail inhibitor (Roche Diagnostics), $25 \mu \mathrm{M}$ sodium fluoride (New England Biolabs, Inc.) and $25 \mu \mathrm{M}$ sodium orthovanadate (New England Biolabs, Inc.), followed by sonication for $1 \mathrm{~min}$ and finally centrifugation at $15,000 \mathrm{x} \mathrm{g}$ for $30 \mathrm{~min}$ at $4^{\circ} \mathrm{C}$. The supernatant containing the total protein lysates was collected and the protein concentrations were measured using a Bradford assay (Bio-Rad Laboratories, Inc.).

A total $30 \mu \mathrm{g}$ proteins were resolved by SDS-PAGE using Mini-PROTEAN precast gels (4-20\%) and $1 \mathrm{X}$ Tris-glycine buffer (Bio-Rad Laboratories, Inc.), and transferred to polyvinylidene difluoride membranes (Bio-Rad Laboratories, Inc.). Subsequently, the membranes were probed with primary mouse anti-human TLK1 antibody (1:200; cat. no. sc-100345, Santa Cruz Biotechnology, Inc.). Then, the membranes were washed 4 times with 1X TBS-0.05\% Tween-20 (TBST) buffer (Thermo Fisher Scientific, Inc.) and incubated with goat anti-mouse antibody conjugated to horseradish peroxidase (HRP; 1:2,000; cat. no. sc-2005, Santa Cruz Biotechnology) using casein blocker (Bio-Rad Laboratories, Inc.) for $12 \mathrm{~h}$ at $4^{\circ} \mathrm{C}$. Following incubation, the membranes were washed 4 times for 5 min with 1X TBS Tween-20 buffer (Thermo Fisher Scientific, Inc.), on an orbital shaker. The loading control was mouse anti-human $\beta$-actin (cat. no. sc-69879; Santa Cruz Biotechnology, Inc.); the secondary antibody was goat anti-mouse IgG-HRP (cat. no. sc-2005, Santa Cruz Biotechnology, Inc.). Signals were measured using Pierce $^{\mathrm{TM}}$ ECLPlus substrate (Thermo Fisher Scientific, Inc.) and viewed under a chemiluminescence imager (Bio-Rad Laboratories). Analysis of the software for densitometric analysis was performed using Image $\mathrm{Lab}^{\mathrm{TM}}$ version 4.1 (Bio-Rad Laboratories, Inc.).

Pooled TLK1 siRNA (si-TLK1) transient transfection. Resuspension of lyophilized ON-TARGETplus pool si-TLKI and pool si-NTG (20 nmol, cat. no. D-001810-10; GE Healthcare Dharmacon, Inc.) was performed using 1X siRNA buffer to yield $100 \mu \mathrm{M}$ stock. Prior to reverse-transfection, $5 \mu \mathrm{M}$ siRNA solution in 1X siRNA buffer was prepared. For experiments requiring 96-well plates, the transfection reagents were prepared in separate tubes. In tube $1,10 \mu 1$ siRNA in serum-free medium was added to $0.5 \mu 15 \mu \mathrm{M}$ siRNA in $9.5 \mu \mathrm{l}$ serum-free medium. In tube 2, $10 \mu \mathrm{l}$ of diluted DF1 transfection reagent (GE Healthcare Dharmacon, Inc.) was prepared in serum-free medium $(0.1 \mu 1$ DF1 with $9.85 \mu 1$ serum-free medium). Both tubes were gently mixed and incubated for $5 \mathrm{~min}$ at room temperature. Subsequently, the contents of tube 1 and 2 were mixed for $20 \mathrm{~min}$ at room temperature. GBM cells (5,000 cells/well) seeded in 96-well plates and a suspension was made with $80 \mu \mathrm{l}$ antibiotic-free complete DMEM per well. The cell suspensions in the antibiotic-free medium were mixed with the previously prepared siRNA, serum-free medium, and transfection reagent in each plate. The cells were incubated for $48 \mathrm{~h}$ (RNA) and $72 \mathrm{~h}$ (protein) at $37^{\circ} \mathrm{C}$ in $5 \% \mathrm{CO}_{2}$. The ON-TARGETplus si-TLK1 sequences used were 5'-GAG UAUGCAAGAUCGAUUA-3', 5'-GAAGCUCGGUCUAUUG UAA-3', 5'-GCAAUGACUUGGAUUUCUA-3' and 5'-GUU CAAAGAUCACCCAACA-3'.

ORF clones and short hairpin RNA (shRNA) transduction. Precision LentiORF lentiviral particle individual clones (cat. no. V13121301) and LentiORF red fluorescent protein (RFP) control (cat. no. OHS5832; Open Biosystems Inc.; Thermo Fisher Scientific, Inc.) were used to overexpress $T L K 1$ in U87MG and LN18 cells following the manufacturer's protocol. The GIPZ shRNA individual clones (cat. nos. V3LHS_637461, V3LHS_637455 and V3LHS_335655) and GIPZ NTG shRNA control clones were purchased in viral particle format (Open Biosystems Inc.; Thermo Fisher Scientific, Inc.) to knockdown TLK1 in the U87MG and LN18 cells. The day prior to transduction, $5 \times 10^{4}$ U87MG or LN18 cells at $40-50 \%$ confluence were seeded onto 24-well tissue culture plates with their respective media. The LentiORF control viral stock was diluted in a round-bottom 96-well plate using serum-free medium in a series of 5-fold dilutions to reach a final dilution of 390,625-fold. Following dilution, the virus stock was pre-incubated for $5 \mathrm{~min}$ at room temperature.

Next, 24-well plates were labelled, using one row per replicate. The culture medium in the 24 -well plates was removed, and then $225 \mu \mathrm{l}$ serum-free medium was added to each well. The cells were transduced by adding $25 \mu$ ldiluted control LentiORF lentivirus from the original 96-well plate to 1 well on the 24 -well destination plate containing the cells. The transduced cultures were incubated at $37^{\circ} \mathrm{C}$ for 4 to $6 \mathrm{~h}$. Subsequently, $1 \mathrm{ml}$ normal concentration DMEM was added and the cells were incubated for $72 \mathrm{~h}$ at $37^{\circ} \mathrm{C}$. The green fluorescent protein (GFP)-expressing cells or cell colonies were counted to determine the functional titre and relative transduction efficiency. Similar methods were used to perform shRNA transduction in both the LN18 and U87MG cell lines. qPCR was then performed as described above to determine successful knockdown and overexpression of the gene of interest. Methods for gene expression by qPCR have been mentioned previously.

Cell viability assay. U87MG and LN18 cells were transfected with $25 \mathrm{nM}$ si-TLK1 in 6-well plates. A total of $10 \mu \mathrm{l}$ PrestoBlue ${ }^{\circledR}$ cell viability reagent (Invitrogen; Thermo Fisher Scientific, Inc.) was added to each well plate. After $1 \mathrm{~h}$ of incubation at $37^{\circ} \mathrm{C}$ readings were taken using a microplate reader, SkanIt RE, for Varioskan Flash 2.4 (Thermo Fisher Scientific, Inc.) at 560/590 nm excitement/emission. Readings were taken at 24, 48, 72 and 96 h post-transfection. Experiments were performed in triplicate. 
Human HT-12 v4 expression BeadChip microarray. Total RNA from U87MG cells was isolated using a RNeasy Plus Mini kit (Qiagen $\mathrm{GmbH}$ ) after 48 h of si-TLK1 transfection. A total of $150 \mathrm{ng}$ purified RNA was amplified using an Illumina Total Prep RNA amplification kit (Life Technologies; Thermo Fisher Scientific, Inc.). Biotin-labelled cRNA was directly hybridized on an Illumina Human HT-12 v4 Expression BeadChip arrays kit (Illumina, Inc.) according to the manufacturer's protocol. Microarray bead chips were scanned using an iScan array scanner (Illumina, Inc.) and the intensity of the data were processed using Genome Studio version 2008.1 (Illumina, Inc.). Analysis was performed using GeneSpring GX 12.6 software (Agilent Technologies, Inc.). Microarray data analysis was performed whereby fluorescent intensities were log-transformed, quantile-normalized, and pre-filtered to remove low-quality data. Principal component analysis was used to assess the data quality control. A moderated unpaired t-test was used to determine the underlying pathways involved following TLK1 knockdown in U87MG cells. P-value computation was conducted using asymptotic theory and Benjamini-Hochberg multiple testing corrections were applied. A significant gene list was obtained where $\mathrm{P}<0.05$ and fold change $>1.1$ were chosen for pathway analysis. Clustering heat maps of differentially expressed genes were constructed using a hierarchy based on Euclidean similarity measure and complete linkage. Gene Set Enrichment Analysis was performed using filtered probe signals with q-value $<0.3$. Pathway analysis was performed using WebGestalt (25) and Pathway Studio 8.0 software (Ariadne Genomics; Elsevier). Protein-protein interaction network analysis was performed to identify possible TLK1 interactors using NetworkAnalyst 3.0 (26).

Single-stranded DNA (ssDNA) apoptosis assay. The cells were seeded in 96 -well plates $\left(3 \times 10^{3}\right.$ cells/well) and transfected with si-TLK1. After $48 \mathrm{~h}$ incubation, the apoptotic activity assay was performed using the ssDNA apoptosis ELISA kit (cat. no. APT225; Chemicon International) according to the manufacturer's protocol. Experiments were performed in triplicate.

Annexin $V$ fluorescence assay. Cells were transfected with si-TLK1 for $48 \mathrm{~h}$ in 6 -well plates. After replacing the media, $2.5 \mathrm{mM}$ temozolomide (TMZ; cat. no. T2577-25MG; Sigma-Aldrich; Merck KGaA) was added to each well. After $48 \mathrm{~h}$ of incubation with $\mathrm{TMZ}$ at $37^{\circ} \mathrm{C}$, cells were harvested. The cells were then washed with PBS and centrifuged at $200 \mathrm{x} g$ for $5 \mathrm{~min}$. The cell pellet was suspended with $100 \mu \mathrm{l}$ of Annexin V-FLUOS (cat. no. 11988549001; Roche Applied Science) labelling solution. Annexin V-FLUOS (20 $\mu \mathrm{l})$ was initially diluted in $1 \mathrm{ml}$ incubation buffer with $20 \mu \mathrm{l}$ propidium iodide solution. The suspension was incubated for 10-15 min at $15-25^{\circ} \mathrm{C}$. Analysis was performed using a $\mathrm{Tali}^{\circledR}$ Image Cytometer (Thermo Fisher Scientific, Inc.). Experiments were performed in triplicate.

Cell cycle assay. The cell cycle assay was performed using $1 \times 10^{6}$ LN18 or U87MG cells transfected with si-TLK1 or si-NTG. The cells were harvested using a standard protocol as described in the Cycletest ${ }^{\mathrm{TM}}$ PLUS DNA Reagent kit protocol
(BD Biosciences). Flow cytometric analysis was performed using BD FACSAria ${ }^{\mathrm{TM}}$ (Becton, Dickinson and Company). Data were analysed using ModFit LT software version 2.0 (Verity Software House, Inc.). Experiments were performed in triplicate.

Colony formation assay. Cells were initially transfected with siRNA or shRNA or pLOC LentiORF-expression vector for $48 \mathrm{~h}$ in T45 flasks prior to the assessment of cell colony formation in the monolayers. At $96 \mathrm{~h}$, cells were trypsinized and washed. Subsequently, 100 cells were counted and seeded on 6-well plates. Colonies were allowed to grow for 14 days. Later, the DMEM was removed and the cells were washed gently with PBS prior to fixation at $25^{\circ} \mathrm{C}$ with $50 \%$ methanol for $10 \mathrm{~min}$ and then staining for $1 \mathrm{~h}$ at room temperature with $0.5 \%$ crystal violet that had been diluted in $50 \%$ methanol. The stain was removed and the cells were washed with distilled water. Colonies was observed using light microscopy (magnification, x40); Nikon Corporation. Colonies containing $>50$ cells were counted to as a single colony. Images of the colonies were captured using ChemiDoc Imager (Bio-Rad Laboratories, Inc.) and automatically counted using openCFU software version 4.0 (27). Experiments were performed in triplicate.

Total/phosphorylated TP53, Erk/AKT/ribosomal protein S6 kinase $\beta-1$ (p70s6k) activation assay. Total/phosphorylated TP53 and Erk/AKT/p70s6k activation assays were performed using InstantOne ${ }^{\mathrm{TM}}$ ELISA kits (cat. nos. 85-86123 and 85-86018, respectively; eBioscience, Inc.). Initially, GBM cell lines were transfected with si-TLK1 as described above and incubated for $72 \mathrm{~h}$. Subsequently, $0.4 \times 10^{6}$ cells were resuspended in $500 \mu \mathrm{l}$ DMEM and incubated for $2 \mathrm{~h}$ at $37^{\circ} \mathrm{C}$. After that, cells were harvested and lysed with agitation (300 RPM) at room temperature for $10 \mathrm{~min}$. Samples, and negative and positive controls supplied by the manufacturer were added to the microplate assay wells. Total/phosphorylated TP53 and Erk/AKT/p70s6k antibodies were added to each well. The microplates were sealed and incubated for $60 \mathrm{~min}$ at room temperature on a plate shaker at 300 RPM. Wells were washed three times with wash buffer and detection reagent was added to each well. After $30 \mathrm{~min}$, the reaction was stopped by adding stop solution. The absorbance at $450 \mathrm{~nm}$ was detected using a VarioSkan Flash multimode plate reader (Thermo Fisher Scientific, Inc.).

Xenograft mouse model. A total of 42 immunodeficient nude mice (female $B A L B / c-n u ; 6$ weeks old; $16-18 \mathrm{~g}$ ) obtained from BioLASCO Taiwan Co., Ltd. were randomly divided into 7 groups and maintained in pathogen-free environments. All animal experiments performed in the present study complied with the international guidelines for the care and treatment of laboratory animals adapted from WHO CHRONICLE, 1985 (28). The animal experiments were approved by the UKM Animal Ethics Committee under the ethics registration number UMBI/2014/ROSLAN/24-SEPT./607-SEPT.-2014-DEC.-2014.

Injection of TLK1-overexpressing and TLK1-knockdown U87MG cells was performed using equal numbers of log-phase U87MG-pGIPZ-NTG, U87MG-pGIPZ-shTLK1-455, U87MG-shTLK1-461, U87MG-pLOC-RFP control or 
U87MG-pLORF-TLK1-301 cells $\left(3 \times 10^{7}\right)$. The cells were harvested, washed in PBS and suspended in $200 \mu \mathrm{l}$ PBS. The cell suspension was injected subcutaneously into the right subdorsal flank tissue of the nude mice to establish subcutaneous xenograft models. The mice were monitored daily 47-day observation period and the sizes of the transplanted tumours were measured by slide calliper every 7 days. A growth curve for the transplanted tumours was plotted after calculating the tumour volume.

The experiment was terminated at day 47 following the completion of observation. The mice were sacrificed and all tumours that had formed subcutaneously were removed and weighed using a Pioneer weighing machine (OHAUS Europe $\mathrm{GmbH}$ ). Tumour tissues and the adjacent tissues were snap-frozen and stored in liquid nitrogen for future study.

Statistical analysis. For the in vitro functional experiments, all data are expressed as the mean \pm standard deviation, and data analysis was performed using appropriate statistical analysis tests, such as Kruskal-Wallis with Dunn's post hoc test, or two-way analysis of variance (ANOVA) with Bonferroni's multiple correction post hoc test. For the xenograft in vivo monitoring experiments, comparisons among all groups were performed using a mixed ANOVA with Bonferroni multiple comparisons test. Tumour weight measurement was performed using Kruskal-Wallis analysis followed by Dunn's multiple comparisons test. For comparisons between two groups, a Mann Whitney U test was utilised. All statistical analyses were performed using GraphPad Prism version 8.0 (GraphPad Software, Inc.). P $<0.05$ was considered to indicate a statistically significant difference.

\section{Results}

RNAi screening in LN18 and U87MG cell lines. In total, 113 upregulated kinase genes were screened and the -kMAD score of each cell line was calculated and sorted using scatter plots (Fig. S1). The scatter plot visualization of the -kMAD clearly demonstrated that Polo-like kinase 1 (PLK1) consistently exhibited the lowest -kMAD value, which was expected as the si-PLK1 was the positive control for each experimental plate. RNAi screening of the LN18 cells identified 20 potential hits involved in cell cycle and checkpoint control regulation, namely aurora kinase A, cyclin dependent kinase inhibitor 1A, cyclin dependent kinase $1(C D C 2)$, NIMA related kinase (NEK)2, NEK8 and TLK1. However, in the U87MG cells, 22 potential hits were identified to serve critical roles in various cellular pathways. Functional clustering analysis using the Database for Annotation, Visualization and Integrated Discovery (DAVID) revealed that the kinases were involved in the cell cycle pathway and focal adhesion pathway. Only $C D C 2$, serine/threonine kinase 33, TLK1, CDC like kinase 2, and cyclin dependent kinase inhibitor 3 were associated with cell cycle and mitosis regulation.

To identify the relevant kinase target for further functional investigations, the 'hit lists' identified from the earlier statistical analysis was overlapped using a Venn diagram (Fig. 1A and B). A total of 4 kinases, $C D C 2, T L K 1$, Fms related tyrosine kinase 3 (FLT3) and $\alpha$ kinase 1 (ALPKI) were overlapped in both cell lines. Further validation was performed on these genes on a small-scale basis. Fig. 1C demonstrated that only TLK1 knockdown significantly decreased the number of viable cells to between 10 and $40 \%(\mathrm{P}<0.05)$. Therefore, TLKI was selected as the potential investigative target in the present study, and its functional role in GBM has also not been established. Fig. S2 demonstrates the efficiency of CDC2, TLK1, FLT3 and ALPK1 mRNA knockdown with their respective siRNA.

Role of TLK1 in modulation of survival and apoptosis pathways. Transient transfection of specific si-TLK1 on U87MG and LN18 cells was performed to analyse the effect of $T L K 1$ on GBM cell proliferation and apoptosis. TLK1 mRNA levels were decreased by $>80 \%$ and TLK 1 protein expression decreased significantly in the si-TLKl-transfected GBM cells (Fig. 2A). There were significantly fewer viable si-TLKI cells compared with the si-NTG cells at $72 \mathrm{~h}$ post-transfection (Fig. 2B); however, the significant decrease in cell viability observed only began at $96 \mathrm{~h}$ after si-TLK1 transfection (Fig. S3).

Apoptosis signals were increased in the 2 GBM cell lines (Fig. 2C and D), mediated by caspase- 3 and caspase-7 activation. Qualitative fluorescence imaging using confocal microscopy indicated increased DEVD complex formation based on the presence of fluorescence green dots (Fig. S4). TLK-1 inhibition also resulted in cell cycle arrest, as demonstrated by a marked increase in S-phase cells and a decrease in $\mathrm{G} 0 / \mathrm{G} 1$ cells $(\mathrm{P}<0.05)$ in both cell lines. Notably, there were significant decreases in the numbers of LN18 cells $(\mathrm{P}<0.05)$ at the $\mathrm{G} 2 / \mathrm{M}$ phase, which was the opposite to the pattern observed in the U87MG cells (Fig. 2E). A marked increase in the number of S-phase cells and a decrease in the number of cells in G0/G1 phase, as indicated by the flow cytometry analysis data (Fig. 2E) may suggest that the cells underwent extensive replication, or that there was an S-phase arrest. By incorporating brdU analysis, it was confirmed that cell replication and proliferation had halted. It was demonstrated that the brdU signal was significantly decreased following TLK1 knockdown in U87MG, as indicated in Fig. S5A.

To determine the effects of TLK1 overexpression on GBM cell proliferation, U87MG cells were transduced with pLOC-ORF clones using lentiviral delivery. Fig. 3A demonstrates the up-to-nearly 20 -fold increase in TLK1 expression in U87MG cells observed compared to empty RFP vector control cells. Transduction efficiency of the TLK1 ORF clones was confirmed by the presence of GFP signals were obtained via fluorescence imaging (Fig. 3B). TLK1 overexpression significantly increased cell viability (Fig. 3C). In Fig. 3D, clonogenicity potential was identified to be increased in the pLOC-TLK1 group. Staining of these colonies was performed using $0.5 \%$ crystal violet (w/v) in $25 \%$ methanol. In addition, the overexpression of TLK1 decreased the levels of apoptosis, as demonstrated by a decrease in Annexin $\mathrm{V}$ signal when incubated with $2.5 \mathrm{mM}$ TMZ (Fig. 3E). BrdU signal levels were increased, suggesting increased DNA synthesis and increased cell proliferation (Fig. 3F); this observation was also supported by increases in percentages of cells in the S-phase, as demonstrated in Fig. S5B.

Chemosensitisation effects of TLK1 inhibition. TLK1 knockdown increased sensitivity of GBM cells to sublethal dose of 


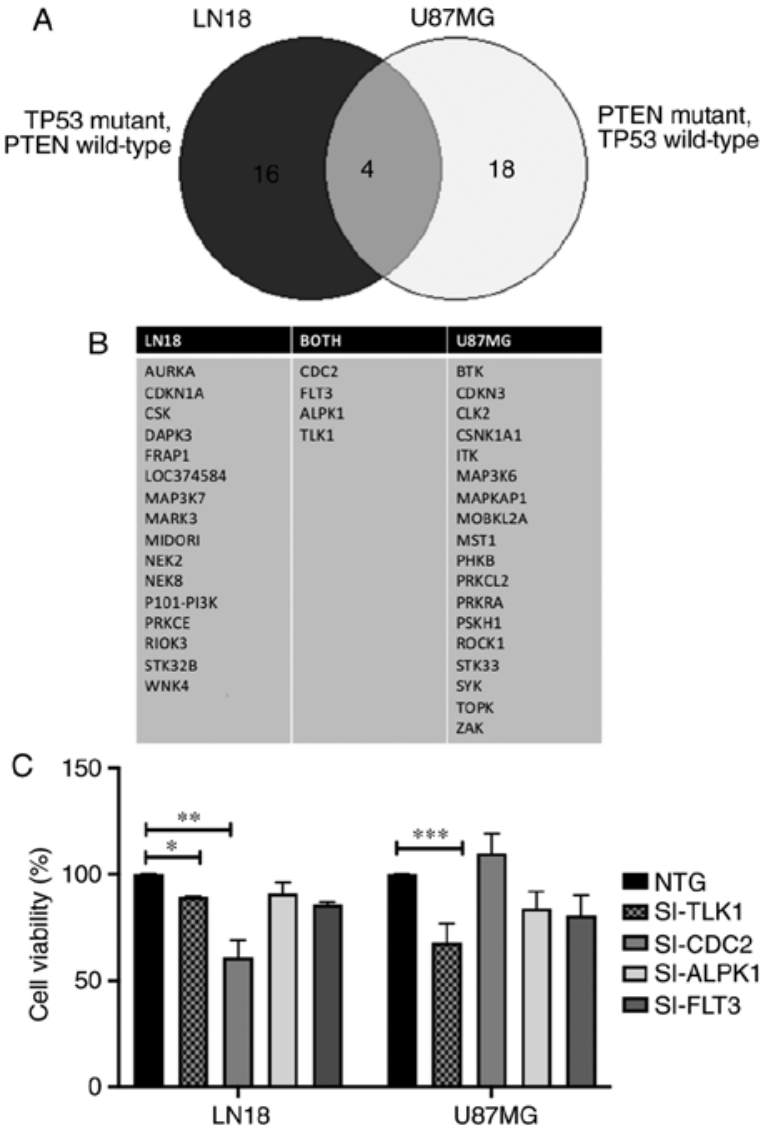

Figure 1. Potential hit genes from RNAi screen targeting the GBM kinome in LN18 and U87MG cells. (A) Venn diagram of the 16 and 18 genes identified by the k-Median Absolute Deviation statistical analysis in LN18 cells and U87MG cells, respectively. A total of 4 genes were consistently present in both cell lines: $C D C 2, T L K 1, F L T 3$ and ALPK1. (B) The complete list of genes identified from RNAi screen. (C) Validation of the 4 genes identified from RNAi screen using Presto Blue assay for cell viability analysis. Readings were performed at $96 \mathrm{~h}$ post-transfection. Analysis were performed using Kruskal-Wallis non-parametric test with Dunn's post hoc test. Values are presented as mean \pm standard deviation of 3 biological replicates. ${ }^{*} \mathrm{P}<0.05,{ }^{* * *} \mathrm{P}<0.01$ and ${ }^{* * *} \mathrm{P}<0.005$. RNAi, RNA interference; GBM, glioblastoma multiforme; TP53, tumor protein 53; $C D C 2$, cyclin dependent kinase 1; $T L K 1$, tousled like kinase 1; FLT3, Fms related tyrosine kinase 3; ALPK1, $\alpha$ kinase 1 ; si, small interference RNA; NTG, non-targeting RNA.

TMZ at $72 \mathrm{~h}$ (Fig. 4A). A significant sensitisation effect was observed $(\mathrm{P}<0.05)$, as demonstrated by a decrease in the colony growth of both cell lines after 14 days incubation following TMZ and si-TLK1 treatment in U87MG cells (Fig. 4B and C). This was due to the decrease in the cellular proliferation through the sublethal dose of $\mathrm{TMZ}$ and apoptosis regulation during TLK1 knockdown.

Microarray gene expression analysis identifies downstream pathways of TLK1. It is important to characterize the genome-wide effect of TLK1 inhibition and to identify cancer cell phenotypes targeted by TLK1 modulation. Microarray analysis identified 527 genes with at least 1.5 -fold change $(\mathrm{P}<0.05)$, with 300 upregulated genes and 227 downregulated genes, and 2,632 genes with 1.1-fold change $(\mathrm{P}<0.05)$. The cell cycle-associated pathways, including cell cycle, DNA replication and G1-S cell cycle control, were significantly sensitive to TLK1 knockdown (Tables I and SI). Fig. 5A demonstrates the network gene interaction between differentially expressed genes identified from the TLK1 knockdown microarray experiment with its potential protein-protein interactome, obtained from network analysis using NetworkAnalyst 3.0. Additional information on nodes and edges are presented in Table SII. Fig. 5B describes the TLK1 hypothetical pathway involved in GBM. We hypothesized that TLK1 may interact with CDC-42 and RAC2 to activate TLK1 downstream signalling for GBM cells to survive.

Role of TLK1 in TP53, AKT and MAPK pathway signalling. Further validation was performed by gene knockdown in GBM cells with shRNA. Data showing that shRNAs were able to decrease the expression level of TLK1 in the tissue targeted are presented in Fig. S6. TP53, AKT and MAPK have key genes in GBM pathogenesis (29). To validate the downstream functional activation of TLK1, the protein markers TP53, AKT1/2/3, p70s6k and extracellular signal-regulated kinase (ERK)1/2/3 were examined using ELISA-based assays. In the TLK1-depleted U87MG cells, the ratio of phosphorylated TP53 to total TP53 protein was significantly increased in the sh-TLK1 GBM cells. However, in the TLK1-overexpressing U87MG cells, the phosphorylated to total TP53 protein signal ratio was decreased significantly. The p70s6k protein signal was significantly decreased in the sh-TLK1 U87MG cells but not in the LN18 cells, suggesting that the inhibition of p70s6k occurred in a TP53-dependant manner. Notably, the protein signals were increased in both TLK1 knockdown cell lines (Fig. S7).

TLK1 knockdown in normal human astrocytes functional analysis. The most important aspect of determining a specific cancer target is its ability to target the specific cancer cells but not their neighbouring normal cells. Knockdown of TLK1 did not cause any significant changes in NHA viability, morphology and apoptosis signals (Fig. S8). These results suggest that TLK1 specifically targets cancer cell lines but not normal astrocytes.

TLK1 knockdown decreases GBM tumour growth in mouse xenografts. Tumour growth was significantly decreased in mice transplanted subcutaneously with U87MG-sh-TLK1-455 or sh-TLK1-461 cells, as observed on days 21, 28 and 35 $(\mathrm{P}<0.05)$. However, on day 42 , the results were not significant (Fig. 6A). On day 47, the mice were sacrificed, and the tumour weights were recorded. The mean tumour weights of the U87MG-sh-455 and U87MG-sh-461 groups were significantly decreased compared to the U87MG-sh-NTG cells $(\mathrm{P}<0.05$; Fig. 6B).

\section{Discussion}

Identification of novel targets by integration of in silico analysis and functional genomics approach. Previous studies have identified several signalling pathways involved in GBM including the p53, retinoblastoma protein, PI3K-PTEN-AKT-mTOR and RAS-ERK pathways (30). In the present study, 2 different GBM cell lines harbouring different mutations were used; LN18 with a TP53 mutation and wild type PTEN and U87MG cells with PTEN mutation and 


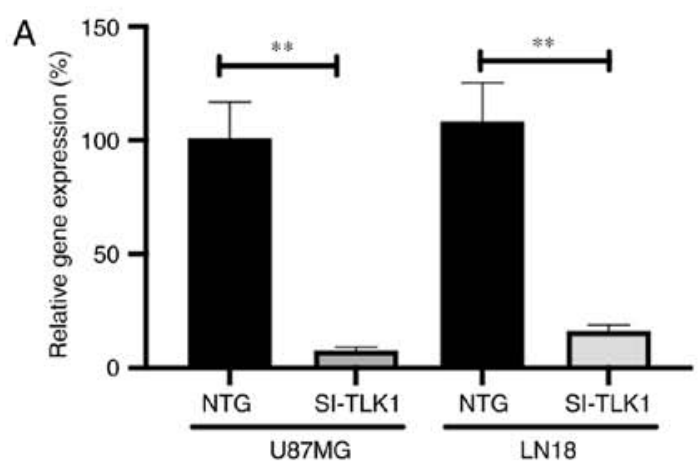

B
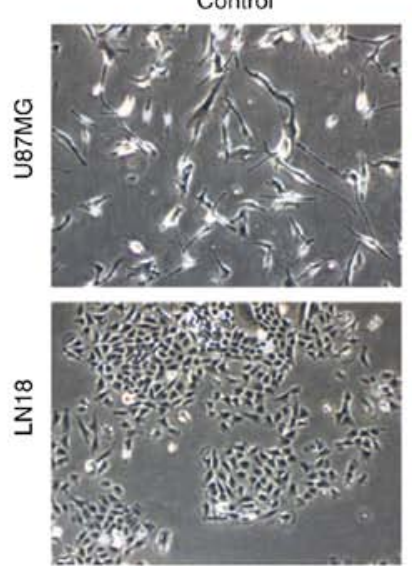

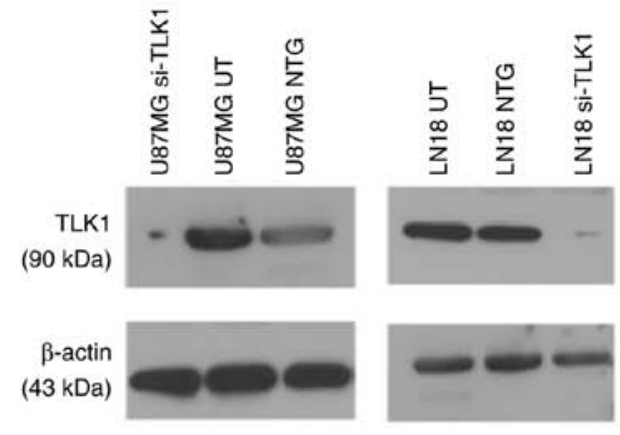

$\mathrm{Ntg}$
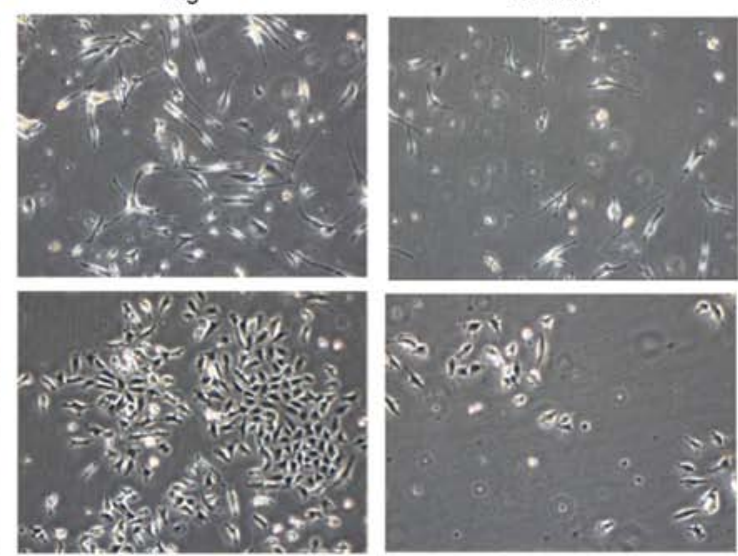
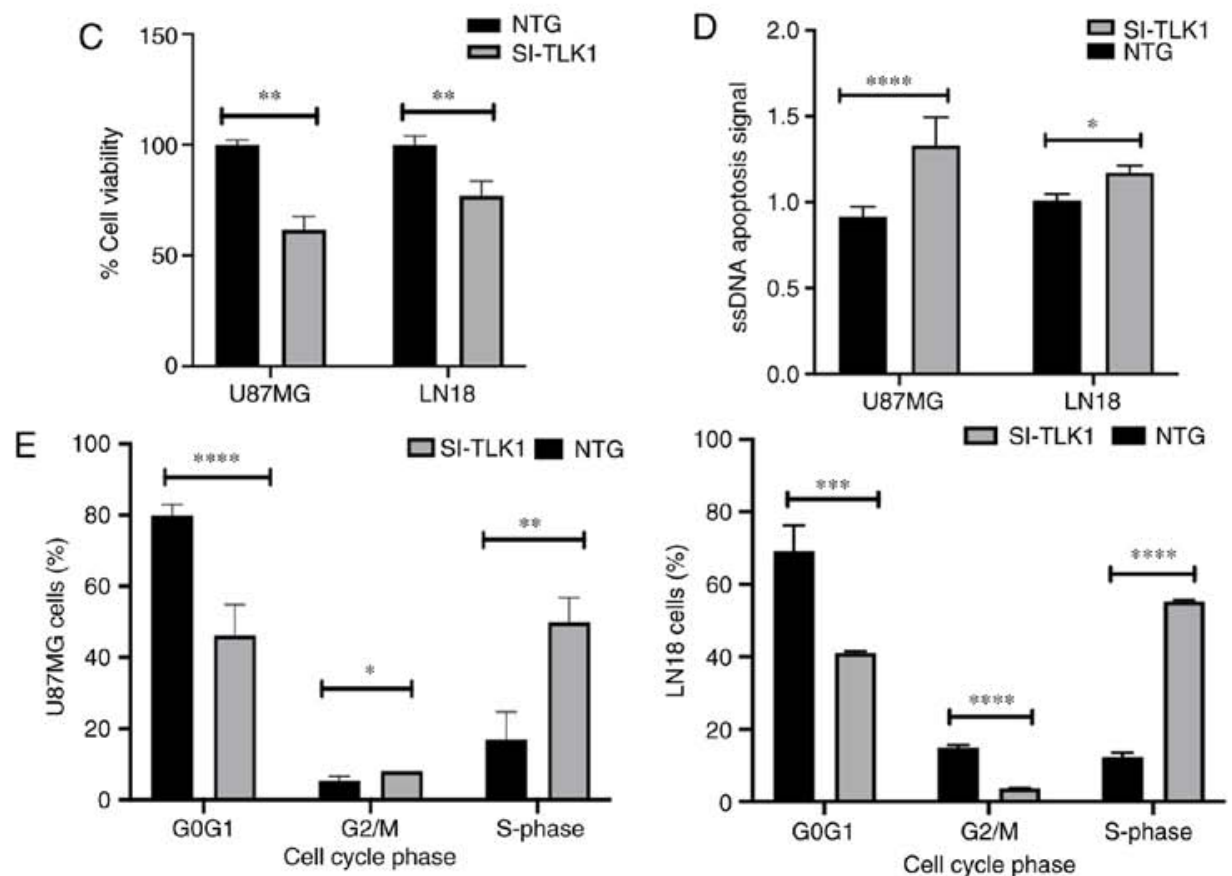

Figure 2. TLK1 knockdown in GBM cells decreases cell viability. (A) Reverse transcription-quantitative polymerase chain reaction and western blot analysis were performed to determine transfection efficiency. TLK1 knockdown in both cell lines was effective, with $>80 \%$ transfection efficiency and decreased TLK1 protein levels at $72 \mathrm{~h}$ post-transfection. (B) TLK1 knockdown caused a decrease in the number of viable cells under an inverted light microscope. (C) Significant decreases in viable U87MG and LN18 cells by 40 and 20\%, respectively, were observed following TLK1 knockdown at 72 h. (D) Increased apoptotic ssDNA signaling in U87MG cells compared with LN18 cells. (E) Cell cycle analysis indicating a marked increase in S-phase and a decrease in G0/G1 using two-way analysis of variance with Bonferroni's multiple correction post hoc test. All experiments were performed in triplicate and the results were compared with the si-NTG control. Values are presented as mean \pm standard deviation of 3 biological replicates. ${ }^{*} \mathrm{P}<0.05,{ }^{* *} \mathrm{P}<0.01,{ }^{* * *} \mathrm{P}<0.005$ and ${ }^{* * * * *} \mathrm{P}<0.001$. TLK1, tousled like kinase 1; GBM, glioblastoma multiforme; ssDNA, single-stranded DNA; si-, small interfering RNA: NTG, non-targeting RNA.

wild-type TP53, which were constructed to mimic common mutations affecting primary GBM. The high-throughput RNAi loss-of-function screen on these 2 different GBM cell lines identified four common targets: $C D C 2, F L T 3, A L P K 1$ and $T L K 1$. These genes are overexpressed in gliomas, particularly GBM (14). 
A
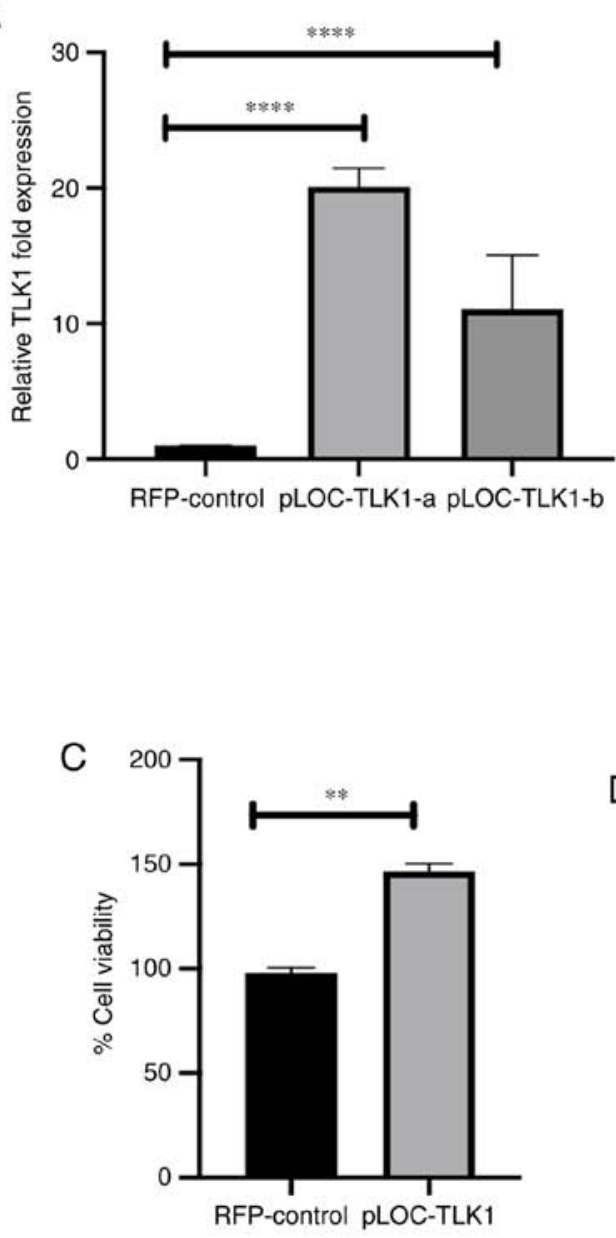

E

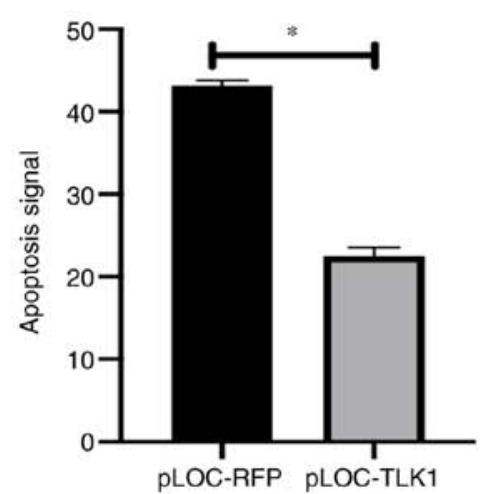

B
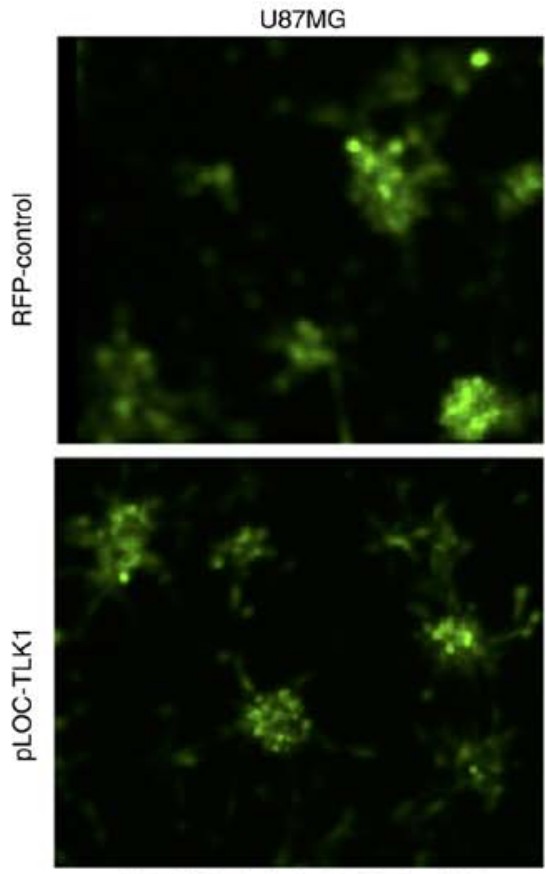

U87MG labelled with Turbo GFP

$\mathrm{D}$
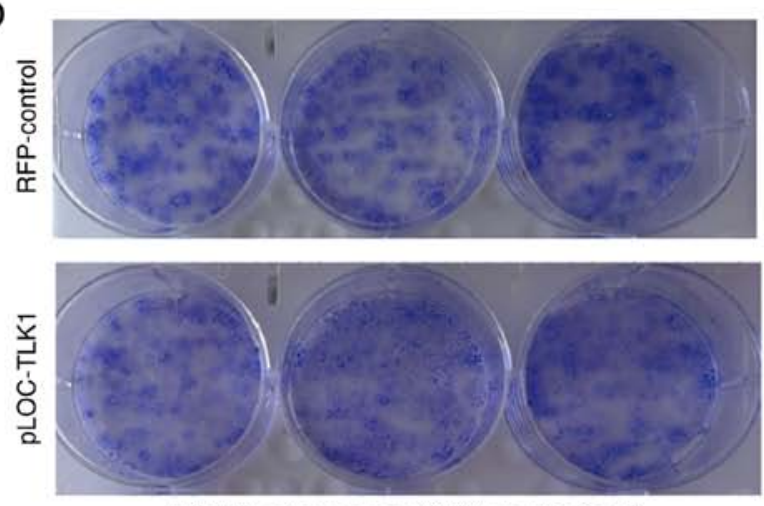

U87MG colony assay ( $0.5 \%$ crystal violet)

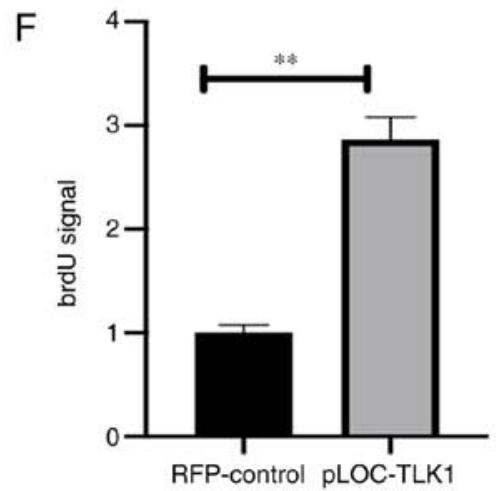

Figure 3. Effects of TLK1 overexpression in U87MG cells. (A) TLK1 mRNA expression following pLOC-TLK1 ORF clone transduction. TLK1 expression was increased by almost 20 -fold. Statistical analysis was performed using Kruskal-Wallis test with Dunn's post hoc test. (B) Presence of GFP signals in each cell confirmed successful transduction of pLOC-TLK1 ORF clone was monitored using fluorescence microscopy (magnification, x100). (C) TLK1 overexpression increased the number of U87MG viable cells by 40\%. (D) Overexpression of TLK1 increased proliferative capability of U87MG-pLOC-TLK1 clones. (E) Apoptosis signals were decreased by 50\% in TLK1 transduced U87MG cells. (F) Increased BrdU signal in TLK1-overexpressing cells. All experiments were performed in triplicate and the results were compared with the si-NTG control and analysed using a Mann Whitney U test. Values are presented as mean \pm standard deviation of 3 biological replicates. ${ }^{*} \mathrm{P}<0.05,{ }^{* * *} \mathrm{P}<0.01$ and ${ }^{* * * * *} \mathrm{P}<0.001$. TLK1, tousled like kinase 1; ORF, open reading frame; RFP, red fluorescent protein; GFP, green fluorescent protein; NTG, non-targeting RNA.

$\mathrm{CDC} 2$ or CDK1 is a key player in cell cycle regulation and highly conserved protein that functions as a serine/threonine kinase. Overexpression of CDC2 promotes oncogenesis and progression of human gliomas and CDC2 knockdown 
A

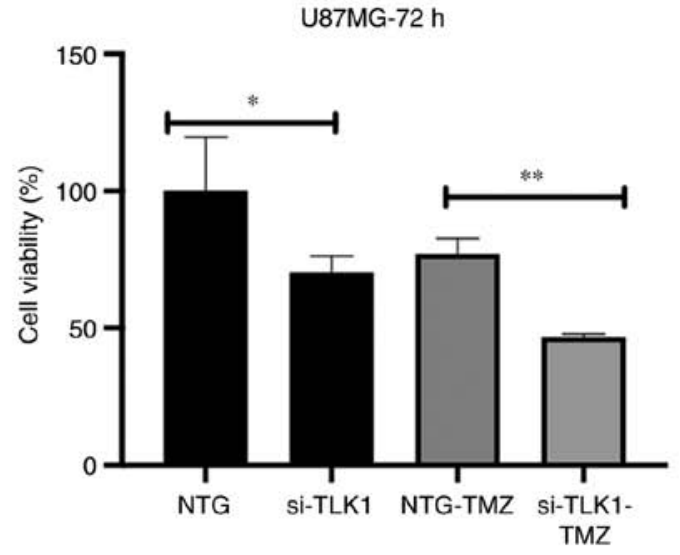

B
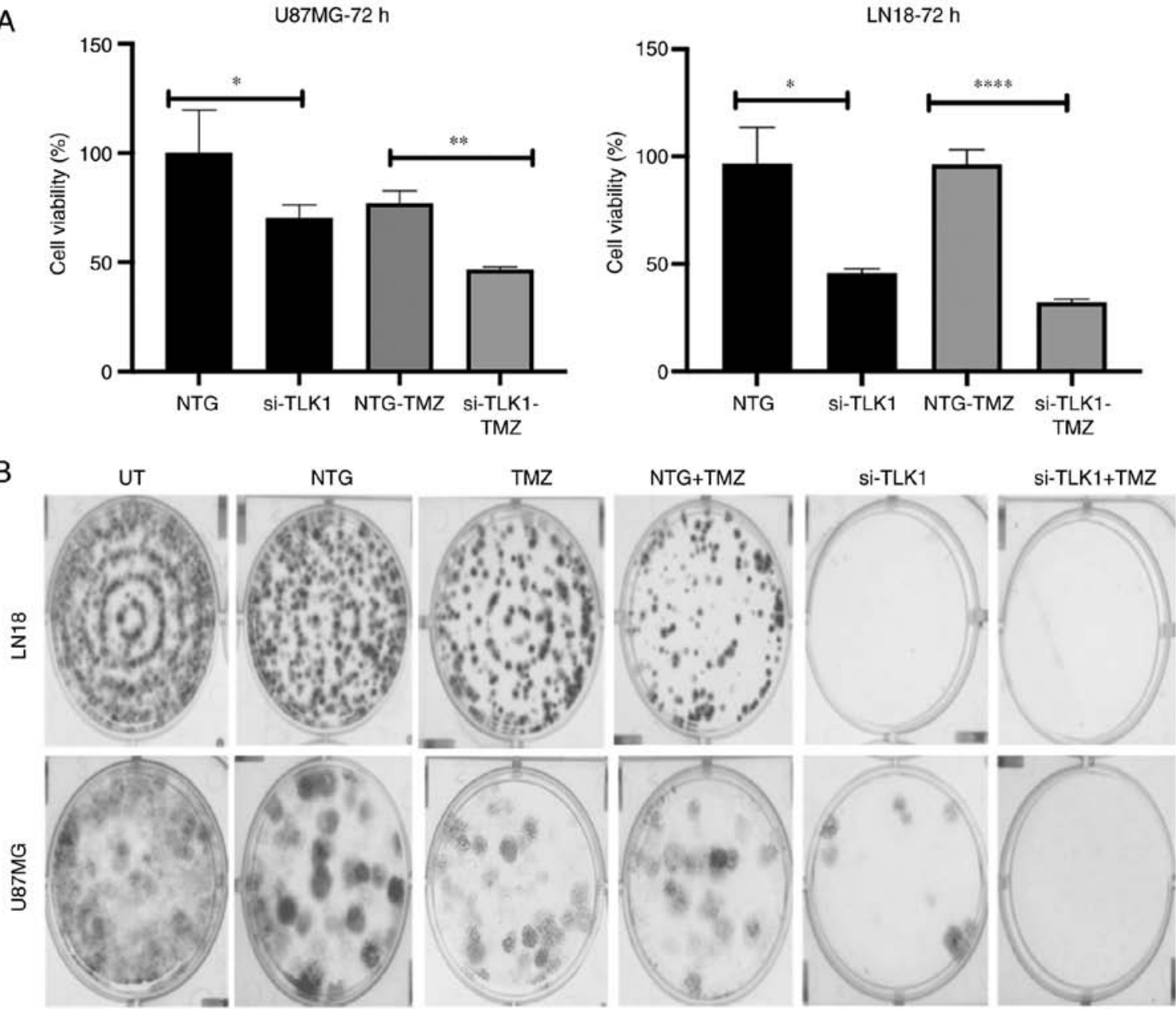

C

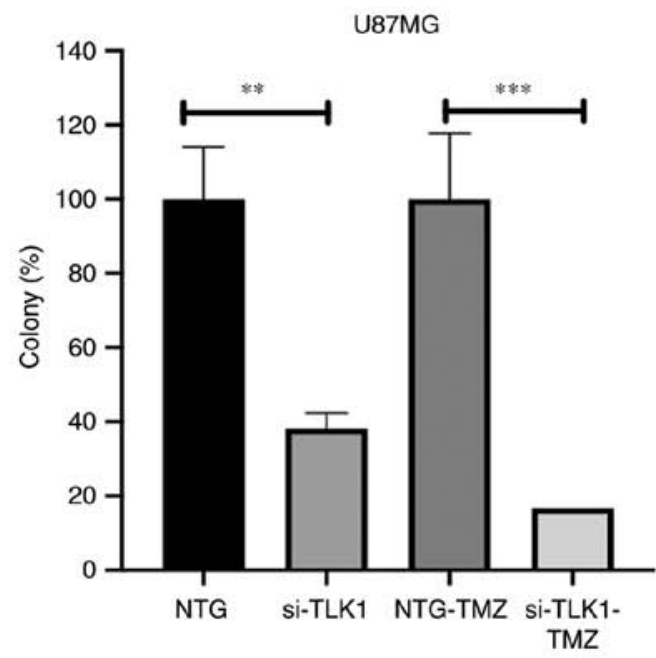

LN18

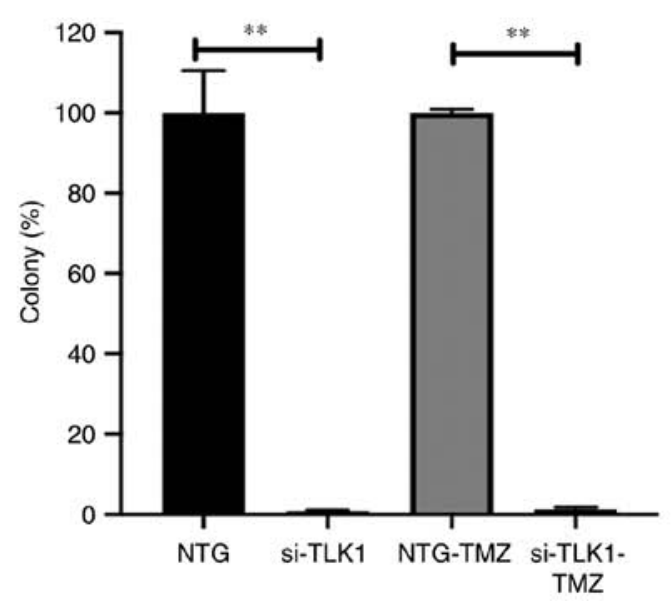

Figure 4. TLK1 knockdown sensitises GBM cells to sublethal dose of TMZ. (A) TLK1 knockdown sensitizes to TMZ at 72 h observed by cell viability assay. (B) Sensitisation effect of TLK1 inhibition in U87MG and LN18 cells colony formation images. (C) Quantitative colony formation assessment of GBM cells treated with si-TLK1 alone and si-TLK1 + TMZ. The colony formation assay confirmed that knockdown of TLK1 sensitised GBM cells to TMZ. Kruskal Wallis was performed with Dunn's multiple correction test. Decreased colony formation observed was due to the decrease in the cellular proliferation and apoptosis. Values are presented as mean \pm standard deviation of 3 biological replicates. ${ }^{*} \mathrm{P}<0.05,{ }^{* *} \mathrm{P}<0.01,{ }^{* * * *} \mathrm{P}<0.005$ and ${ }^{* * * * *} \mathrm{P}<0.001$. TLK1, tousled like kinase 1; GBM, glioblastoma multiforme; TMZ, temozolomide; si-, small interfering RNA; NTG, non-targeting RNA.

decreases cell proliferation by causing an increase in the number of G2M cell cycle arrest (31).

ALPK1 comes from the family atypical kinases. The $\alpha$ kinase family has been demonstrated to be mutated in various types of cancer (32). ALPK1 has been implicated in epithelial cell polarity and exocytic vesicular transport towards the apical plasma membrane (33). ALPK1 is located on Golgi-derived vesicles, where it phosphorylates myosin IA, an apical vesicle transport motor protein that regulates the delivery of vesicles to the plasma membrane (33). 
Table I. Functional pathway analysis identified statistically significant pathways affected by TLK1 knockdown in U87MG cells.

\begin{tabular}{lrc}
\hline Pathway name & Gene & Statistics \\
\hline Cell cycle & 39 & $2.70 \times 10^{-31}$ \\
DNA replication & 27 & $7.26 \times 10^{-31}$ \\
G1 to S cell cycle control & 26 & $1.78 \times 10^{-20}$ \\
DNA damage response & 17 & $5.30 \times 10^{-11}$ \\
TGF $\beta$ signaling pathway & 19 & $1.53 \times 10^{-7}$ \\
TSH signaling pathway & 10 & 0.0001 \\
Wnt signaling pathway & 8 & 0.0003 \\
Focal adhesion & 16 & 0.0003 \\
Parkin-ubiquitin proteosomal system & 9 & 0.0006 \\
pathway & & \\
TOR signaling & 6 & 0.0013 \\
Wnt signaling pathway and pluripotency & 10 & 0.0013 \\
Interleukin-11 signaling pathway & 7 & 0.0013 \\
Integrin-mediated cell adhesion & 10 & 0.0013 \\
Signaling pathways in glioblastoma & 9 & 0.0016 \\
Sphingolipid metabolism & 5 & 0.0016 \\
Mismatch repair & 4 & 0.0016 \\
TNF- $\alpha$ signaling pathway & 10 & 0.0019 \\
Apoptosis & 9 & 0.0026 \\
Regulation of actin cytoskeleton & 12 & 0.0035 \\
MAPK signaling pathway & 12 & 0.0051 \\
\hline
\end{tabular}

Pathway analysis was performed using the WebGestalt server on 2,632 differentially expressed genes (1.1-fold change). Cell cycle, DNA replication and G1 to $\mathrm{S}$ cell cycle control were amongst the top affected pathways during TLK1 knockdown. These data were concordant with the functional assay results.

FLT3, a class 3 RTK, serves an important role in the regulation of normal haematopoiesis. It was identified in relatively high abundance in astrocytic tumours but without detection of any activating FLT3 mutations involved (34). Activating mutations in FLT3, particularly involving internal tandem duplications in the juxta membrane domain, are detected in $\sim 30 \%$ of adult and $15 \%$ of childhood AMLs (35) suggesting that the types of FLT3 abnormalities in GBM differ from leukaemia. Bleeker et al (36) identified that FLT3 was one of the frequent genes that contained somatic mutations in GBM. Overexpression of FLT3 ligand (FLT3LG) in GBM cells may provide a positive advantage in activating the anti-tumour immune response (37). King et al (38) indicated that combination therapy with adenoviral FLT3LG and adenoviral thymidine kinase therapy had successfully eradicated multifocal brain tumour disease in a syngeneic, intracranial GBM model (38).

In the present study, less commonly reported kinase-associated genes were also identified as positive hits as well-established kinases such as $E G F R$, platelet derived growth factor receptor and mitogen-activated protein kinase 3 were intentionally excluded from the RNAi screening during the candidate target selection, as the major aim was to identify novel kinase targets in GBM. Revalidation of these 4 candidate targets revealed that knockdown of TLK1 consistently resulted in decreased cell viability. In addition, the role of TLK1 in GBM is not fully understood. TLK1 is a serine threonine kinase (STK) homologous to the Tousled gene in Arabidopsis thaliana, which is required for normal flower and leaf development $(39,40)$. There are 2 types of TLK: TLK1 and TLK2, which are highly conserved in mammals (41). TLK1 activity is cell cycle-dependent and regulates chromatin dynamics, including DNA replication, DNA repair, transcription and chromosome segregation $(42,43)$. TLK1 is a potential novel therapeutic target in GBM, as this gene may control GBM cell growth and survival. TLK is absent in yeast, suggesting that TLK homologs are present only in higher forms of eukaryotes (41). A massive screening of 125 STKs identified frequently altered STKs in different tumour types. However, due to the lack of glioblastoma samples, the study was unable to identify the significance of TLK1 in glioblastoma (44).

TLK1-regulated mechanisms of GBM cell survival, proliferation and apoptosis. Knockdown of TLK1 in GBM cells significantly decreased cell viability, clonogenicity potential and DNA synthesis. In addition, TLK-1 inhibition also induced downstream activation of caspase-3 and caspase-7 intrinsic apoptosis pathway. Similar results were also reported by Carrera et al (41), whereby $T L K 1$ activity was decreased in a loss-of-function mutation induced in Drosophila, causing nuclear division arrest at interphase accompanied by apoptosis. Alternatively, it may activate a different novel form of programmed cell death that is independent of caspase activation (45). Notably, NHA cells were not affected by $T L K 1$ knockdown, suggesting that the effects of $T L K 1$ inhibition maybe specific to $T L K 1$-overexpressing cancer cells and the growth and survival of the adjacent normal cells will not be disrupted. The results of the present study were in concordance with those reported by Segura-Bayona et al, in which a decreased colony formation in TLK1-knockdown cells, particularly in the mouse embryonic fibroblasts cell lines, was observed, suggesting that TLK1 is required to maintain genomic instability and integrity as well as cellular viability (46). A limitation of the present study was the inability to check for TLK1 protein expression due to time and funding limitations, although the efficiency of TLK1 knockdown at the mRNA level in NHA was examined. Also, a limitation of the present study was that cell viability was not examined at different time points $(24,48$ or $96 \mathrm{~h}$ ), which would have been necessary to gain insight in the proliferative capability of GBM cells.

TLK1 serves an important role in regulating DNA replication, mitosis and cytokinesis $(47,48)$. TLK1 knockdown inhibits DNA replication and this was supported by the results of the present study. However, the mechanisms of inhibition in U87MG and LN18 cells differ slightly. TLK1 knockdown in U87MG cells decreased the number of G0/G1 cells, slightly increased the G2/M cells, and increased S-phase arrest, whilst LN18 cells at G0/G1 and G2/M were decreased but the $\mathrm{S}$-phase arrest increased significantly (49). The mechanism of S-phase arrest and decrease in G0/G1 cells concurs with the microarray results of the present study, which involved downregulation of proliferative genes, namely CCND1, and 


\section{A}

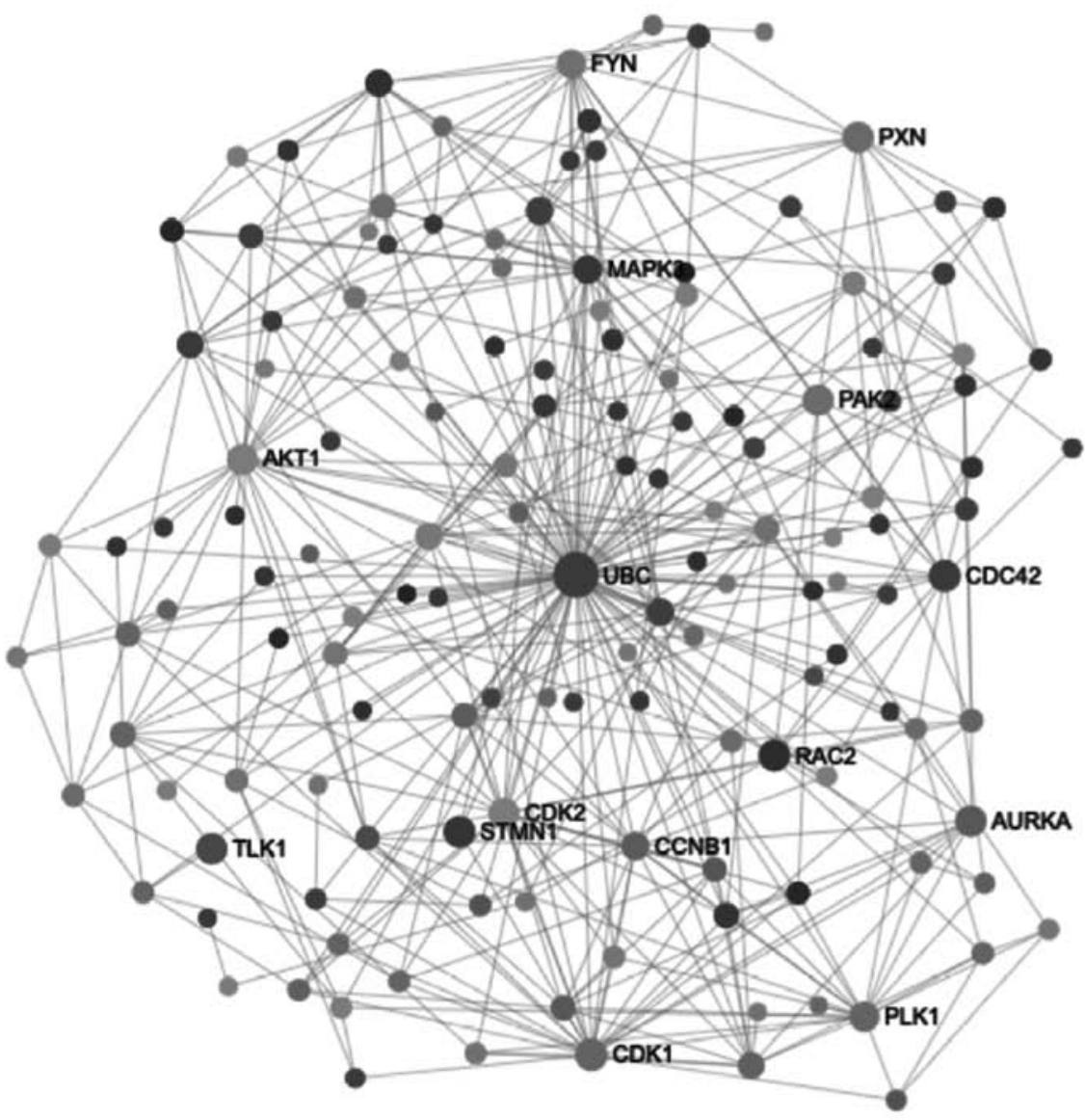

B

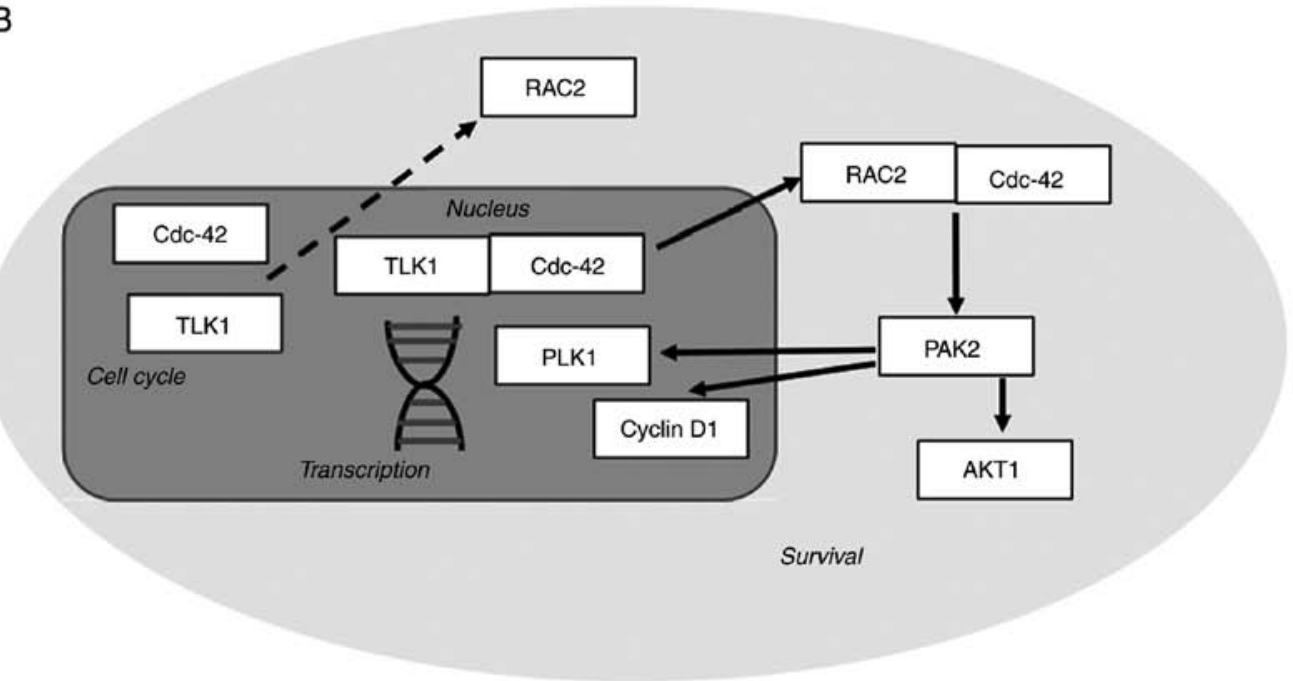

Figure 5. Analysis of TLK1 interactome and hypothetical pathway. (A) TLK1 network identified from network analysis identifies 1 subnetwork consists of 626 nodes and 1,831 edges. Nodes were then filtered based on enriched KEGG pathways P<0.01. (B) Hypothetical model of the TLK1RAC2CDC42PAK2 regulation pathways in GBM. CDC42 is localized within the nucleus together with TLK1. CDC42, being a small Ras GTPbinding protein, may bind to TLK1 and be a substrate for TLK1. Activated CDC42 in the nucleus binds or interacts with activated TLK1 protein kinase to emit signals to the other CDC42 binding protein that is localized in the cytoplasm, to induce binding with activated RAC2. In other cases, activated CDC42 may bind to activate TLK1 and later be released into the cytoplasm to emit signal while binding with RAC2. In a homeostatic environment, CDC42 and RAC2 will bind to p21 protein, which becomes activated PAK2 and emits signals for other downstream molecules. PAK2 signals AKT1 for the regulation of survival pathways. PAK2 also regulates cell cycle activity with PLK1 and cyclin D1 for initiation of transcriptional machinery. TLK1, tousled like kinase 1; CDC42, cell division cycle 42; RAC2, Rac family small GTPase 2; PAK2, p21 (RAC1) activated kinase 2; AKT1, AKT serine/threonine kinase 1.

the upregulation of the tumor suppressor gene transforming growth factor $\beta 1$. G2/M was observed to be slightly increased in U87MG cells with wild-type TP53 expression, suggesting that these cells undergo normal DNA repair (50). However, with the downregulation of the cell division cycle (CDC)25A and CDC25B genes, it may suggest that these cells cannot undergo further mitosis, but alternatively undergo apoptosis. An increase in the number of $\mathrm{G} 2 / \mathrm{M}$ cells may provide evidence 

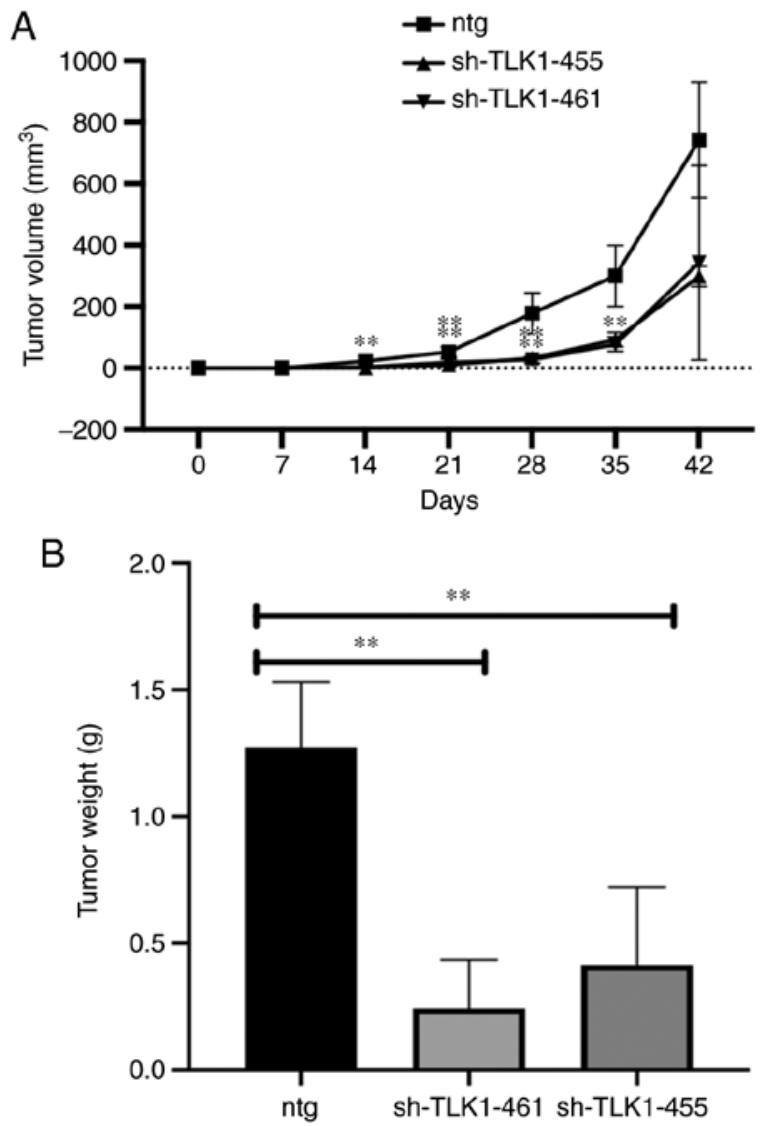

Figure 6. TLK1 knockdown decreases tumorigenicity in nude mice. (A) Tumour sizes were determined by measuring the tumour volume every 5 days from day 7 to 42 following injection. Data analysis was performed using mixed ANOVA with Bonferroni multiple comparisons test, in which $\mathrm{P}<0.05$ was considered to indicate a statistically significant difference. (B) Average tumour weights of mice 40 days following injection. Values are presented as means \pm standard deviation from 5 independent samples. Data were analysed using Kruskal-Wallis test. ${ }^{* *} \mathrm{P}<0.05$.

of $\mathrm{G} 2 / \mathrm{M}$ phase cell cycle arrest, supported by molecular data (50). These results were observed in a fibroblast cell line (BSF), in which TLK1 knockdown depleted spindle formation and chromosome segregation (48), but not in fibroblasts with TLK2 knockdown (47), thereby disrupting cellular mitotic activity. Wang et al (51) suggested that TP53 status affected the patients' response towards DNA topoisomerase inhibitor CPT-11. They also demonstrated that in a primary culture of glioblastoma cells with wild-type TP53 expression, CDC2 phosphorylation was disrupted in a TP53-dependent manner.

It was also demonstrated that $T L K 1$ overexpression in GBM cells increased proliferation and resistance to apoptosis. This is in line with previous data, where $T L K 1$ overexpression in breast and prostate cancer resulted in resistance to radiotherapy (52). By contrast, Zhang et al (53) observed that TLK1 overexpression in Drosophila eyes induced cell death and pigmentation loss, suggesting that TLK1 may serve a different role in eye development.

Regulation of downstream TLK1 survival pathways. Different key kinases were implicated in the U87MG and LN18 cells. In wild-type TP53 and mutant PTEN U87MG cells, TLK1 knockdown significantly downregulated and deactivated p70s6k (Thr389). The 70-kDa ribosomal P70S6 kinase is a downstream target of the PI3K/mTOR pathway that regulates cell growth and G1 cell cycle progression by inducing the cellular translational machinery (54). P70s6k is commonly upregulated in breast cancer and GBM $(55,56)$. Harada et al (57) demonstrated that the function of p70s6k was not limited to just protein synthesis and growth maintenance. The IGF-1 cytokine signals p70s6k to control cell survival by inhibiting the proapoptotic BAD through phosphorylation. Therefore, p70s6k deficiency activates the proapoptotic BAD, and vice versa (56).

The levels of phosphorylated TP53 was increased, confirming that the mechanism of apoptosis occurs via a TP53-dependent pathway. Simultaneously, CDC42 (Rho GTPase) activation following TLK1 knockdown indicated activation of the apoptosis signalling pathway. Volarević and Thomas (58) suggested that activation of the TP53-dependent apoptosis activation does not only occur by $B A X$ induction, but also via upregulation of the activation of the membrane-bound CDC42 in cancer cells with wild-type TP53 (58). By contrast, Tu and Cerione (59) suggested that CDC42 is actually a substrate for caspase-3 and caspase-7, which is associated with Fas-induced apoptosis via the $\mathrm{NF}-\kappa \mathrm{B}$ pathway. Decreased CDC42 activity in TLK1-overexpressing cells increased cell growth, was in concordant with the results reported by Warner et al (60).

Chemo sensitization of GBM cells by TLK1 knockdown. Activation of the $O$-6-methylguanine-DNA methyltransferase (MGMT) repair enzyme, which repairs TMZ-generated $O$-6-methylguanine-DNA adducts, causes TMZ resistance in GBM cells (61). The presence of MGMT inherently activates base excision repair and mismatch repair (62). A synthetic lethality screen identified genes such as MRPI and WEE1 that increase chemo sensitization towards TMZ $(63,64)$. In the present study, $T L K 1$ was identified to be an important target for sensitizing GBM cells to TMZ. TLK1 is also involved in DNA damage and DNA repair, whereby TLK1 kinase activity decreases in response to genotoxic stress, such as ionizing radiation or hydroxyurea treatment $(65,66)$.

Takayama et al (67) demonstrated that TLK1 inhibition sensitized cholangiocarcinoma cells to the platinum-based cytotoxic compound cisplatin (67). Ronald et al (52) indicated that $T L K 1$ knockdown significantly sensitized DU45 prostate cancer cells to radiation. In the present study, knockdown of TLK1 sensitized GBM cells to TMZ, in particular the U87MG cells harbouring PTEN mutations but with wild-type TP53 expression. TMZ induces DNA damage by forming DNA adducts and promotes G2 and S-phase arrest (68). In glioma cells, wild-type TP53 expression has the capability of sensitizing the GBM cells to anti-cancer drugs, and this supports the results of the present study demonstrating that knockdown of TLK1 sensitized U87MG cells to TMZ, which is consistent with other studies (69-71). In contrast, GBM cells with mutant TP53 are resistant to TMZ (72). Simultaneous inhibition of TLK1 may cause global and enhanced cell cycle arrest at both G2-M and $\mathrm{S}$ phases, synergizing the effects of TMZ on GBM cell growth inhibition. However, not all chemotherapeutic agents are suitable for $T L K 1$ sensitization (67). 
TLK1 inhibition decreases GBM growth in a subcutaneous xenograft mouse model. The functional role of TLK1 in regulating GBM growth in female $B A L B / c-n u$ mice was investigated. The subcutaneous xenograft growth rate of TLK1-knockdown GBM cells was significantly decreased. Ronald et al (73) performed a PC-3 xenograft model study in SCID/bg mice to examine the in vivo effects of a TLK1 inhibitor, the anti-psychotic thioridazine. Notably, oral administration of thioridazine significantly decreased the rate of tumour growth. Therefore, future work may involve combining thioridazine and TMZ in GBM models to examine its effectiveness and efficacy.

In conclusion, our in vitro functional analyses suggest TLK1 serves important roles in GBM cell survival, cell cycle, proliferation and apoptosis. The in vivo animal model also demonstrated the role of TLK1 in tumour growth. Therefore, TLK1 may therefore serve as a promising potential target in GBM therapy.

\section{Acknowledgements}

The authors would like to thank Professor Rodney J Scott from University of Newcastle, Australia for his critical comments in this project.

\section{Funding}

The present study was funded by a Higher Institution Centre of Excellence (HICoE) research grant (grant no. JJ-015-2011), Ministry of Higher Education, Malaysia.

\section{Availability of data and materials}

All data generated or analysed during this study are included in this published article.

\section{Authors' contributions}

KI conceived and designed the experiments, performed the experiments, analysed the data, contributed reagents/materials/analysis tools, wrote the manuscript and prepared figures and tables. NAAM performed the microarray experiments and reviewed drafts of the manuscript. RH conceived and designed the experiments, and reviewed drafts of the manuscript. RJ was the principal investigator, and was involved in data analysis and reviewing of manuscript drafts. All authors read and approved the final manuscript.

\section{Ethics approval and consent to participate}

The animal experiments were approved by the UKM Animal Ethics Committee (approval no. UMBI/2014/ROSLAN/24SEPT./607-SEPT.-2014-DEC.-2014).

\section{Patient consent for publication}

Not applicable.

\section{Competing interests}

The authors declare that they have no competing interests.

\section{References}

1. Johnson DR and O'Neill BP: Glioblastoma survival in the United States before and during the temozolomide era. J Neurooncol 107: 359-364, 2012.

2. Paw I, Carpenter RC, Watabe K, Debinski W and Lo HW: Mechanisms regulating glioma invasion. Cancer Lett 362: 1-7, 2015.

3. Stupp R, Mason WP, van den Bent MJ, Weller M, Fisher B, Taphoorn MJ, Belanger K, Brandes AA, Marosi C, Bogdahn U, et al: Radiotherapy plus concomitant and adjuvant temozolomide for glioblastoma. N Engl J Med 352: 987-996, 2005.

4. Petropoulos C, Guichet P-O, Masliantsev K, Wager M and Karayan-Tapon L: Functional invadopodia formed in glioblastoma stem cells are important regulators of tumor angiogenesis. Oncotarget 9: 20640-20657, 2018.

5. Micallef J, Taccone M, Mukherjee J, Croul S, Busby J, Moran MF and Guha A: Epidermal growth factor receptor variant III-induced glioma invasion is mediated through myristoylated alanine-rich protein kinase $\mathrm{C}$ substrate overexpression. Cancer Res 69: 7548-7556, 2009.

6. Muller PAJ and Vousden KH: p53 mutations in cancer. Nat Cell Biol 15: 2-8, 2013

7. Kubiatowski T, Jang T, Lachyankar MB, Salmonsen R, Nabi RR, Quesenberry PJ, Litofsky NS, Ross AH and Recht LD: Association of increased phosphatidylinositol 3-kinase signaling with increased invasiveness and gelatinase activity in malignant gliomas. J Neurosurg 95: 480-488, 2001.

8. Brandes AA, Franceschi E, Tosoni A, Hegi ME and Stupp R: Epidermal growth factor receptor inhibitors in neuro-oncology: Hopes and disappointments. Clin Cancer Res 14: 957-960, 2008.

9. Vivanco I, Robins HI, Rohle D, Campos C, Grommes C, Nghiemphu PL, Kubek S, Oldrini B, Chheda MG, Yannuzzi N, et al: Differential sensitivity of glioma-versus lung cancer-specific EGFR mutations to EGFR kinase inhibitors. Cancer Discov 2: 458-471, 2012.

10. Mrugala MM and Chamberlain MC: Mechanisms of disease: Temozolomide and glioblastoma-look to the future. Nat Clin Pract Oncol 5: 476-486, 2008.

11. Foukas LC, Berenjeno IM, Gray A, Khwaja A and Vanhaesebroeck B: Activity of any class IA PI3K isoform can sustain cell proliferation and survival. Proc Natl Acad Sci USA 107: 11381-11386, 2010.

12. Yuan TL and Cantley LC: PI3K pathway alterations in cancer: Variations on a theme. Oncogene 27: 5497-5510, 2008.

13. Faes S and Dormond O: PI3K and AKT: Unfaithful partners in cancer. Int J Mol Sci 16: 21138-21152, 2015.

14. Rhodes DR, Yu J, Shanker K, Deshpande N, Varambally R, Ghosh D, Barrette T, Pandey A and Chinnaiyan AM: ONCOMINE: A cancer microarray database and integrated data-mining platform. Neoplasia 6: 1-6, 2004.

15. Bredel M, Bredel C, Juric D, Harsh GR, Vogel H, Recht LD and Sikic BI: High-resolution genome-wide mapping of genetic alterations in human glial brain tumors. Cancer Res 65: 4088-4096, 2005.

16. Liang Y, Diehn M, Watson N, Bollen AW, Aldape KD, Nicholas MK, Lamborn KR, Berger MS, Botstein D, Brown PO and Israel MA: Gene expression profiling reveals molecularly and clinically distinct subtypes of glioblastoma multiforme. Proc Natl Acad Sci USA 102: 5814-5819, 2005.

17. Shai R, Shi T, Kremen TJ, Horvath S, Liau LM, Cloughesy TF, Mischel PS and Nelson S: Gene expression profiling identifies molecular subtypes of gliomas. Oncogene 22: 4918-4923, 2003.

18. Lee J, Kotliarova S, Kotliarov Y, Li A, Su Q, Donin NM, Pastorino S, Purow BW, Christopher N, Zhang W, et al: Tumor stem cells derived from glioblastomas cultured in bFGF and EGF more closely mirror the phenotype and genotype of primary tumors than do serum-cultured cell lines. Cancer Cell 9: 391-403, 2006.

19. Sun L, Hui AM, Su Q, Vortmeyer A, Kotliarov Y, Pastorino S, Passaniti A, Menon J, Walling J, Bailey R, et al: Neuronal and glioma-derived stem cell factor induces angiogenesis within the brain. Cancer Cell 9: 287-300, 2006.

20. Manning G, Whyte DB, Martinez R, Hunter T and Sudarsanam S: The protein kinase complement of the human genome. Science 298: 1912-1934, 2002. 
21. Birmingham A, Selfors LM, Forster T, Wrobel D, Kennedy CJ, Shanks E, Santoyo-Lopez J, Dunican DJ, Long A, Kelleher D, et al: Statistical methods for analysis of high-throughput RNA interference screens. Nat Methods 6: 569-575, 2009.

22. Chung N, Zhang XD, Kreamer A, Locco L, Kuan PF, Bartz S, Linsley PS, Ferrer M and Strulovici B: Median absolute deviation to improve hit selection for genome-scale RNAi screens. Biomol Screen 13: 149-158, 2008.

23. Zhang XD, Yang XC, Chung N, Gates A, Stec E, Kunapuli P, Holder DJ, Ferrer M and Espeseth AS: Robust statistical methods for hit selection in RNA interference high-throughput screening experiments. Pharmacogenomics 7: 299-309, 2006.

24. Livak KJ and Schmittgen TD: Analysis of relative gene expression data using real-time quantitative PCR and the 2(-Delta Delta C(T)) method. Methods 25: 402-408, 2001

25. Wang J, Duncan D, Shi Z and Zhang B: WEB-based GEne SeT analysis toolkit (WebGestalt): Update 2013. Nucleic Acids Res 41: W77-W83, 2013.

26. Zhou G, Soufan O, Ewald J, Hancock REW, Basu N and Xia J: NetworkAnalyst 3.0: A visual analytics platform for comprehensive gene expression profiling and meta-analysis. Nucleic Acids Res 47: 234-241, 2019.

27. Geissmann Q: OpenCFU, a new free and open-source software to count cell colonies and other circular objects. PLoS One 8: e54072, 2013.

28. Howard-Jones N: A CIOMS ethical code for animal experimentation. WHO Chron 39: 51-56, 1985.

29. Crespo I, Vital AL, Gonzalez-Tablas M, Patino Mdel C, Otero A, Lopes MC, de Oliveira C, Domingues P, Orfao A, Tabernero MD, et al: Molecular and genomic alterations in glioblastoma multiforme. Am J Pathol 185: 1820-1833, 2015.

30. Cancer Genome Atlas Research Network: Comprehensive genomic characterization defines human glioblastoma genes and core pathways. Nature 455: 1061-1068, 2008.

31. Chen H, Huang Q, Dong J, Zhai DZ, Wang AD and Lan Q: Overexpression of CDC2/CyclinB1 in gliomas, and CDC2 depletion inhibits proliferation of human glioma cells in vitro and in vivo. BMC Cancer 8: 29, 2008.

32. Greenman C, Stephens P, Smith R, Dalgliesh GL, Hunter C, Bignell G, Davies H, Teague J, Butler A, Stevens C, et al: Patterns of somatic mutation in human cancer genomes. Nature 446 $153-158,2007$

33. Middelbeek J, Clark K, Venselaar H, Huynen MA and van Leeuwen F: The alpha-kinase family : An exceptional branch on the protein kinase tree. Cell Mol Life Sci 67: 875-890, 2010.

34. Eßbach C, Andrae N, Pachow D, Warnke JP, Wilisch-Neumann A, Kirches E and Mawrin C: Abundance of Flt 3 and its ligand in astrocytic tumors. Onco Targets Ther 6: 555-561, 2013.

35. Kottaridis PD, Gale RE, Frew ME, Harrison G, Langabeer SE, Belton AA, Walker H, Wheatley K, Bowen DT, Burnett AK, et al: The presence of a FLT3 internal tandem duplication in patients with acute myeloid leukemia (AML) adds important prognostic information to cytogenetic risk group and response to the first cycle of chemotherapy: Analysis of 854 patients from the United Kingdom Medical Research Council AML 10 and 12 trials. Blood 98: 1752-1759, 2001.

36. Bleeker FE, Lamba S, Zanon C, Molenaar RJ, Hulsebos TJ, Troost D, van Tilborg AA, Vandertop WP, Leenstra S, van Noorden CJ and Bardelli A: Mutational profiling of kinases in glioblastoma. BMC Cancer 14: 718, 2014.

37. Ali S, King G, Curtin J, Candolfi M, Xiong W, Liu C, Puntel M, Cheng Q, Prieto J, Ribas A, et al: Combined immunostimulation and conditional cytotoxic gene therapy provide long-term survival in a large glioma model. Cancer Res 65: 7194-7204, 2005.

38. King GD, Muhammad AK, Curtin JF, Barcia C, Puntel M, Liu C, Honig SB, Candolfi M, Mondkar S, Lowenstein PR and Castro MG: Flt3L and TK gene therapy eradicate multifocal glioma in a syngeneic glioblastoma model. Neuro Oncol 10 : 19-31, 2008.

39. Roe JL, Rivin CJ, Sessions RA, Feldmann KA and Zambryski PC: The Tousled gene in A. thaliana encodes a protein kinase homolog that is required for leaf and flower development. Cell 75 939-950, 1993.

40. Roe JL, Nemhauser JL and Zambryski PC: TOUSLED participates in apical tissue formation during gynoecium development in Arabidopsis. Plant Cell 9: 335-353, 1997.

41. Carrera P, Moshkin YM, Gronke S, Sillje HHW, Nigg EA, Jackle $\mathrm{H}$ and Karch F: Tousled-like kinase functions with the chromatin assembly pathway regulating nuclear divisions. Genes Dev 17: 2578-2590, 2003
42. Silljé HH, Takahashi K, Tanaka K, Van Houwe G and Nigg EA Mammalian homologues of the plant Tousled gene code for cell-cycle-regulated kinases with maximal activities linked to ongoing DNA replication. EMBO J 18: 5691-5702, 1999.

43. De Benedetti A: The tousled-like kinases as guardians of genome integrity. ISRN Mol Biol 2012: 627596, 2012.

44. Capra M, Nuciforo PG, Confalonieri S, Quarto M, Bianchi M, Nebuloni M, Boldorini R, Pallotti F, Viale G, Gishizky ML, et al: Frequent alterations in the expression of serine/threonine kinases in human cancers. Cancer Res 66: 8147-8154, 2006.

45. Xiang W, Zhang D, Montell DJ and Brill J: Tousled-like kinase regulates cytokine-mediated communication between cooperating cell types during collective border cell migration. Mol Biol Cell 27: 12-19, 2015.

46. Segura-Bayona S, Knobel PA, González-Burón H, Youssef SA, Peña-Blanco A, Coyaud É, López-Rovira T, Rein K, Palenzuela L, Colombelli J, et al: Differential requirements for Tousled-like kinases 1 and 2 in mammalian development. Cell Death Differ 24: 1872-1885, 2017.

47. Li Z, Gourguechon S and Wang CC: Tousled-like kinase in a microbial eukaryote regulates spindle assembly and S-phase progression by interacting with Aurora kinase and chromatin assembly factors. J Cell Sci 120: 3883-3894, 2007.

48. Li Z, Umeyama T and Wang CC: The chromosomal passenger complex and a mitotic kinesin interact with the tousled-like kinase in trypanosomes to regulate mitosis and cytokines. PLoS One 3: e3814, 2008.

49. Zhao T, Sun Q, del Rincon SV, Lovato A, Marques M and Witcher M: Gallotannin imposes S phase arrest in breast cancer cells and suppresses the growth of triple-negative tumors in vivo. PLoS One 9: e92853, 2014.

50. DiPaola RS: To arrest or not to $\mathrm{G}_{2}-\mathrm{M}$ cell-cycle arrest. Clin Cancer Res 8: 3311-3314, 2002.

51. Wang Y, Zhu S, Cloughesy TF, Liau LM and Mischel PS: p53 disruption profoundly alters the response of human glioblastoma cells to DNA topoisomerase I inhibition. Oncogene 23: 1283-1290, 2004.

52. Ronald S, Sunavala-Dossabhoy G, Adams L, Williams B and De Benedetti A: The expression of tousled kinases in $\mathrm{CaP}$ cell lines and its relation to radiation response and DSB repair. Prostate 71: 1367-1373, 2011.

53. Zhang Y, Cai R, Zhou R, Li Y and Liu L: Tousled-like kinase mediated a new type of cell death pathway in Drosophila. Cell Death Differ 23: 146-157, 2015.

54. Minami Y, Endo S, Okumura S, Shibukawa K, Sasaki T and Ohsaki Y: Activating the prostaglandin $\mathrm{I}_{2}$-IP signaling suppresses metastasis in lung cancer. Cancer Res 72, 2012.

55. Heinonen H, Nieminen A, Saarela M, Kallioniemi A, Klefström J, Hautaniemi S and Monni O: Deciphering downstream gene targets of $\mathrm{PI} 3 \mathrm{~K} / \mathrm{mTOR} / \mathrm{p} 70 \mathrm{~S} 6 \mathrm{~K}$ pathway in breast cancer. BMC Genomics 9: 348, 2008.

56. Pelloski CE, Lin E, Zhang L, Yung WK, Colman H, Liu JL, Woo SY, Heimberger AB, Suki D, Prados M, et al: Prognostic associations of activated mitogen-activated protein kinase and Akt pathways in glioblastoma. Clin Cancer Res 12: 3935-3942, 2006.

57. Harada H, Andersen JS, Mann M, Terada N and Korsmeyer SJ: p70S6 kinase signals cell survival as well as growth, inactivating the pro-apoptotic molecule BAD. Proc Natl Acad Sci USA 98: 9666-9670, 2001

58. Volarević S and Thomas G: Role of S6 phosphorylation and S6 kinase in cell growth. Prog Nucleic Acid Res Mol Biol 65: 101-127, 2001.

59. Tu S and Cerione RA: Cdc42 is a substrate for caspases and influences Fas-induced apoptosis. J Biol Chem 276: 19656-19663, 2001.

60. Warner SJ, Yashiro H and Longmore GD: The Cdc42/Par6/aPKC polarity complex regulates apoptosis-induced compensatory proliferation in epithelia. Curr Biol 20: 677-686, 2010.

61. Zhang X, Zhang W, Cao WD, Cheng G and Zhang YQ: Glioblastoma multiforme : Molecular characterization and current treatment strategy (Review). Exp Ther Med 3: 9-14, 2012.

62. Zhang J, Stevens MFG and Bradshaw TD: Temozolomide: Mechanisms of action, repair and resistance. Curr Mol Pharmacol 5: 102-114, 2012.

63. Pokorny JL, Calligaris D, Gupta SK, Iyekegbe DO Jr, Mueller D, Bakken KK, Carlson BL, Schroeder MA, Evans DL, Lou Z, et al: The efficacy of the Weel inhibitor MK-1775 combined with temozolomide is limited by heterogeneous distribution across the blood-brain barrier in glioblastoma. Clin Cancer Res 21: 1916-1924, 2015 
64. Tivnan A, Zakaria Z, O'Leary C, Kögel D, Pokorny JL, Sarkaria JN and Prehn JH: Inhibition of multidrug resistance protein 1 (MRP1) improves chemotherapy drug response in primary and recurrent glioblastoma multiforme. Front Neurosci 9: 218, 2015.

65. Groth A, Lukas J, Nigg EA, Silljé HH, Wernstedt C, Bartek J and Hansen K: Human Tousled like kinases are targeted by an ATM- and Chk1-dependent DNA damage checkpoint. EMBO J 22: 1676-1687, 2003.

66. Krause DR, Jonnalagadda JC, Gatei MH, Sillje HH, Zhou BB, Nigg EA and Khanna K: Suppression of Tousled-like kinase activity after DNA damage or replication block requires ATM, NBS1 and Chk1. Oncogene 22: 5927-5937, 2003.

67. Takayama Y, Kokuryo T, Yokoyama Y, Ito S, Nagino M, Hamaguchi M and Senga T: Silencing of Tousled-like kinase 1 sensitizes cholangiocarcinoma cells to cisplatin-induced apoptosis. Cancer Lett 296: 27-34, 2010.

68. Cui B, Johnson SP, Bullock N, Ali-Osman F, Bigner DD and Friedman HS: Decoupling of DNA damage response signaling from DNA damages underlies temozolomide resistance in glioblastoma cells. J Biomed Res 24: 424-435, 2010.

69. Hermisson M, Klumpp A, Wick W, Wischhusen J, Nagel G, Roos W, Kaina B and Weller M: O6-methylguanine DNA methyltransferase and p53 status predict temozolomide sensitivity in human malignant glioma cells. J Neurochem 96: 766-776, 2006.
70. Martin S, Janouskova $\mathrm{H}$ and Dontenwill $\mathrm{M}$ : Integrins and p53 pathways in glioblastoma resistance to temozolomide. Front Oncol 2: 157, 2012.

71. Roos WP, Batista LF, Naumann SC, Wick W, Weller M, Menck CFM and Kaina B: Apoptosis in malignant glioma cells triggered by the temozolomide-induced DNA lesion O6-methylguanine. Oncogene 26: 186-197, 2007.

72. Blough MD, Beauchamp DC, Westgate MR, Kelly JJ and Cairncross JG: Effect of aberrant p53 function on temozolomide sensitivity of glioma cell lines and brain tumor initiating cells from glioblastoma. J Neurooncol 102: 1-7, 2011.

73. Ronald S, Awate S, Rath A, Carroll J, Galiano F, Dwyer D, Kleiner-Hancock H, Mathis JM, Vigod S and De Benedetti A: Phenothiazine inhibitors of TLKs affect double-strand break repair and DNA damage response recovery and potentiate tumor killing with radiomimetic therapy. Genes Cancer 4: 39-53, 2013. Attribution 4.0 International (CC BY 4.0) License. 